Revista lus et Praxis, Año 18, No 1, 2012, pp. $151-186$

ISSN 0717 - 2877

Universidad de Talca - Facultad de Ciencias Jurídicas y Sociales

"La relación como objeto de la

Ciencia del Derecho Penal"

Edison Carrasco Jiménez

\title{
LA RELACIÓN COMO OBJETO DE LA CIENCIA DEL DERECHO PENAL*
}

\section{THE RELATIONSHIP AS A SCIENTIFIC OBJECT OF CRIMINAL LAW SCIENCE}

EDISON CARRASCO JIMÉNEZZ*

\begin{abstract}
RESUMEN
Por regla general, la "relación" como categoría central ha sido desestimada tanto por la filosofía como por la ciencia del derecho, cuestión que sin duda repercute en la ciencia del derecho penal. El presente artículo tiene por fin denotar este vacío, y presentar algunas claves por las que podría centrarse el estudio de la ciencia penal en la relación en cuanto objeto científico. Para ello, en primer lugar, se hará un estado de la cuestión en la tratativa de la relación por la filosofía y por la ciencia del derecho, para, en segundo lugar, centrarnos en las posibilidades de entender la relación como objeto de la ciencia del derecho penal.
\end{abstract}

ABSTRACT

As a general rule, the "relationship" as a central theme has been overlooked as much by the field of philosophy as by legal science, which, without doubt, has repercussions on criminal justice science. This article will demonstrate this gap, and present some key points to show that the study of criminal law science of the relationship as a scientific object. Thus, in the first instance this article will explain the state of this matter (how "the relation" has been overlooked) in relation to philosophy and legal science; and in the second instance, it will concentrate on the possibilities of understanding this relationship as a scientific object of criminal law science.

PaLABRAS CLAVE

La Relación, Objeto de la Ciencia Penal, Relación Penal, Relación Normativa KEYWORDS

The Relationship, Object of Criminal Law Science, Criminal Relationship, Normative Relationship

\section{ObSERVACIONES PRELIMINARES}

El presente trabajo puede corresponder perfectamente con un avance de una investigación, puesto que teniendo como centro la "relación" como objeto de

\footnotetext{
*Trabajo recibido el 22 de marzo y aprobado el 27 de abril de 2012.

** Doctor (C) Derecho Penal por la Universidad de Salamanca, España; investigador, Centro Telúrico de Investigaciones Teóricas (CTIT); Abogado Asesor (s), USEXVI, Fiscalía Nacional. Correo electrónico: ecarrasj@hotmail.com.
} 
la ciencia penal, el objetivo es efectuar un sucinto estado de la cuestión en la tratativa de la relación tanto por la filosofía como por la ciencia del derecho, dejando así un piso desde el cual poder, al menos, poner en el tapete la discusión sobre la relación como objeto de la ciencia penal. Por ende, no se pretenden dar fórmulas metodológicas para trabajar la relación dentro de la ciencia penal en tanto objeto, sino más bien ésta es una aproximación a su estudio, una definición de materias, una declaración de principios, si se quiere.

\section{TRATATIVA DE LA RELACIÓN EN LA FILOSOFÍA}

\section{De Aristóteles a la escolástica}

El pensamiento filosófico occidental, abre la discusión epistemológica sobre el objeto, fundándolo particular y prioritariamente sobre la "cosa".

Así la cosa ha sido un punto dominante en la filosofía y el pensamiento en general. No se puede negar que en Aristóteles, la preocupación sobre la "cosa" sea central, y que todo su andamiaje filosófico descanse necesariamente en las diversas aproximaciones sobre la cosa y su fundamento. No por nada Zucchi, a propósito de la filosofía de aquél, señale: "Estamos asistiendo por primera vez en Occidente a la creación de un orden nuevo, el orden del logos y la razón discursiva. Se trata de convertir la primera experiencia de la cosa, es decir, de la primera cosa (Ur-ding), en el nuevo orden instaurado por el logos"1 [énfasis del autor suplido]. En efecto, sólo traer a colación las discusiones sobre la ousía, repare en lo dicho. Ni siquiera vale la pena traer a colación a la res, y todas sus implicancias e importancia superlativa no sólo a nivel filosófico -por ejemplo, Descartes y las sabidas distinciones de res cogitans y res extensa-.

En este contexto, la "relación" es relegada a un segundo término, reducida al campo de las categorías, donde, y en palabras de Hartmann, la doctrina filosófica, larga y tenazmente la ha mantenido como algo secundario².

En efecto, la forma de tratamiento que Aristóteles otorga a la relación, es fundamentalmente en cuanto categoría. El sistema descriptivo de las relaciones que efectúa a través del Órganon (Categorías) y de la Metafísica, traza un sistema clasificatorio, un tanto confuso, acerca de los tipos de relaciones. Así existen dos de este tipo que parece distinguir con mayor precisión, que son las "relaciones accidentales" y las "relaciones de potencia". Las demás se de-

\footnotetext{
1 Zucchl, Hernán, "Introducción”, en Aristóteles, Metafísica, [trad. Hernán Zucchi], Debolsillo, Buenos Aires, 2004, pp. 13-99, p. 93.

${ }^{2}$ Hartmann, Nicolai, Ontología, Vol. IV. Filosofía de la naturaleza. Teoría especial de las categorías. (Categorías dimensionales. Categorías Cosmológicas), p. 284.
} 
ducen, como las "numéricas", las de "género-especie", la de "atributo". Todas funcionan en base a ser entendidas dentro del sistema de las diez categorías ${ }^{3}$, y en estrecho vínculo con la idea de lo relativo ${ }^{4}$ ( $\pi \rho$ ò $\left.\tau i ́\right)$ o ad aliquid. No hay muchas diferencias entre ellas, desde que mantienen una constante, que es el entroncarse con una cualidad determinada, cualidad que está definida a nivel meramente conceptual y abstracto. Al definir la cualidad "doble que", una relación numérica que la contenga puede ser expresada como "4 es el doble de 2", o en una relación accidental se podría decir que "Sócrates es el doble de sabio que Platón". Esto supone que ambas no son diferentes, en cuanto se remiten a una cualidad específica conceptualmente señalada ("doble") y que, en el sentido descrito por Aristóteles, es relativa a ("doble qué"). Pero tales cualidades son, por efectos de la naturaleza relacionada, cualidades comparativas, sea que se exprese en cualidades comparadas (como "lo bello de lo menos bello" ${ }^{\prime \prime}$, "el doble con relación a la mitad"6), o bien en cualidades donde se expresa tal cualidad ("aquello que calienta a lo que es calentado, lo que corta a lo que es cortado" ${ }^{\prime \prime}$ ). Ello no puede ser entendida de otra forma, desde que las cosas son entendidas en relación con algo ${ }^{8}$, como "cosas de otras cosas" ${ }^{\prime}$, como "todas las cosas (...) que no se dicen sino de otras cosas"10 o "se refieren a otras cosas que ellas mismas"11. Con ello parece ser que la relación es lo que se predica de algo, y como tal, dependiente de la cosa. Así, la cuadratura del círculo (cosa) es independiente de la ciencia que estudiando el fenómeno, haya de relacionarse a ella ${ }^{12}$. O el objeto (cosa) que provoca sensaciones, es independiente de la sensación a ella relacionada, con lo que la sensación no depende de ella para su existencia ${ }^{13}$. Pero si algo es independiente de la cosa respecto de la otra para su existencia, la "reciprocidad" que nota Aristóteles de las cosas en relación, parece abrir otro juicio respecto del carácter de depen-

\footnotetext{
${ }^{3}$ Aristóteles, "Categorías", Sección segunda, Capítulo IV, § 1, p. 24.

${ }^{4}$ ArIstóteles, "Categorías", cit. nota n. 2, Capítulo VII, §1, p. 31.

${ }^{5}$ Aristóteles, "Categorías", cit. nota n. 2, § 27, p. 35.

${ }^{6}$ Aristóteles, La Metafísica de Aristóteles, 1020b15, p. 269.

${ }^{7}$ Aristóteles, La Metafísica, cit. nota n. 6 1020b28-29, p. 270

${ }^{8}$ Aristóteles, "Categorías", § 3, p. 32; Aristóteles, La Metafísica, cit. nota n. 6 1020b15-1020b30, pp. 269-270.

${ }^{9}$ Aristóteles, "Categorías", cit. nota n. 2, Capítulo VII, § 1, p. 31; § 2, p. 32

${ }^{10}$ Aristóteles, "Categorías", cit. nota n. 2, § 2, p. 32.

11 Aristóteles, "Categorías", cit. nota n. 2, § 3, p. 32.

12 Aristóteles, "Categorías", cit. nota n. 2, § 19, p. 34.

${ }^{13}$ Aristóteles, "Categorías", cit. nota n. 2, § 21, p. 34.
} 
dencia. Si no puede entenderse el esclavo del señor, o el señor del esclavo ${ }^{14}$, de tal manera que sin señor no hay esclavo ${ }^{15}$, entonces una cosa no puede existir sin la otra, pero no en el sentido óntico (el señor sigue siendo "hombre", sin depender del esclavo para esta existencia), sino para darle sentido y significación al concepto, no como mera cualidad, sino como expresión de una realidad, que sin la esclavitud o dominio como relación, no tendría significado. Así, para Aristóteles, si en cosas que están bajo relación, la destrucción de una cosa supone la destrucción de otra ${ }^{16}$, entonces quiere decir que existe entre ambas reciprocidad y, por ende, dependencia mutua. Y en cuanto, según el estagirita, puede haber relaciones de las que no exista denominación ${ }^{17}$, significa la posibilidad de pervivencia de relaciones que no se crean a partir de conceptos ya definidos, sino que éstas existan con anterioridad y con independencia de un sistema de conceptos. Toda esta última idea, se aparta del concepto clásico de relación que viene sosteniéndose del discurso de Aristóteles, en cuanto categoría, sino que parece reconocer además una concepción diferente, no ligada al mundo de los conceptos, sino más bien diferente y no dependiente del tal. La relación así, se aleja de un nivel de dependencia óntica, para producir un tipo de autonomía diverso de lo óntico de las cosas. Poseen, en cambio, una suficiencia propia, donde las cosas en relación, parecen integrarse en otra cosa que sólo ellas mismas: sin dejar su ente, comparten una ontología distinta.

La escolástica no deja de entender a la relación como categoría, y ésta es la consideración principal y casi única de lo heredado por el estagirita de aquélla ${ }^{18}$. El gran punto de inflexión se encuentra en Tomás de Aquino quien extiende las posibilidades teóricas de la relación. No deja, en todo caso, de no considerar a la relación en cuanto categoría ${ }^{19}$ y, por ende, en tanto accidente ${ }^{20}$, con lo cual la relación es dependiente de las cosas entre las que se establece tal relación ${ }^{21}$. Sitúa un sistema clasificatorio y conceptual más sólido y más detallado que el aristotélico. Como siendo el estagirita su base, pareciese recoger, además de la relación en cuanto categoría, la segunda de las concepciones de relación que

${ }^{14}$ Aristóteles, "Categorías", cit. nota n. 2, § 4, p. 32; § 13, p. 33.

${ }^{15}$ Aristóteles, "Categorías", cit. nota n. 2, § 15, p. 33.

${ }^{16}$ Aristóteles, "Categorías", cit. nota n. 2, § 17, p. 33.

17 Una denominación puede no existir para una relación existente (ARISTÓTElES, "Categorías", cit. nota n. 2 , § 16, p. 33; § 19, p. 34).

${ }^{18}$ Como Avicena, quien señalaba previamente la categoría de "relación" para los vínculos entre materia y forma (Avicena, Sobre metafísica, pp. 94-99), o expresados para la divinidad (Ibíd., pp. 148-150).

${ }^{19}$ Aquino, Tomás de, Summa Theologica, Tomo Primus, p. 197.

${ }^{20}$ Aquino, Tomás de, Summa, cit. nota n. 19, Quaestio XXVIII, Art. I, p. 197.

${ }^{21}$ Aquino, Tomás de, Summa, cit. nota n. 19, p. 197-198. 
habría señalado Aristóteles. Es así como, en aras de esta taxonomía, establece Aquino la distinción entre relación ideal y real, y entre relación ad aliquid e in aliquo. El primer tipo de distinción sitúa la relación ideal, racional o de la razón, como aquellas producidas por la aprensión de la mente ${ }^{22}$. La relación rea ${ }^{23}$, en cambio, es aquella producida en la realidad (en la experiencia) o que se produce por naturaleza (como "la cosa grave se relaciona con su centro" ${ }^{24}$, que en el hoy hablaríamos de gravedad). Esta distinción es interesante, porque parece denotar de manera más clara, la duplicidad en Aristóteles, es decir, la obvia consideración de la relación en cuanto categoría, papel que bien podría cumplir en el aquinate, las relaciones ideales, pero, además, la relación real, que parece corresponder a este segundo momento en el estudio de las relaciones del estagirita, esto es, la relación en tanto no dependiente de las cosas. Esto se ve aún más reforzado, al asumir Aquino sus dos clasificaciones restantes: las relaciones ad aliquid e in aliquo y las relativas y absolutas.

En efecto, tratándose del primer grupo de relaciones recién mencionado (ad aliquid e in aliquo), tal concepto de relación continúa con la tradición aristotélica del carácter ad aliquid de éste, pero el aquinate expande su significado. Las relaciones ad aliquid en Aquino son evidentemente comparativas entre cosas. Pero el segundo tipo de relaciones in aliquo ${ }^{25}$, fuera de ser hasta cierto punto introducción del aquinate en el esquema de Aristóteles, son más bien una relación de la cosa consigo misma, donde relación y cosa es lo mismo ("in Deo non est aliud esse relationis et essentiae, sed unum et idem"26). Esta última clasificación resulta curiosa, porque prescinde de dos términos o cosas relacionables, para establecer una relación de la cosa consigo misma. Fuera de las críticas que se le señalaren al aquinate posteriormente por OCCAM ${ }^{27}$,

\footnotetext{
${ }^{22}$ Aquino, Tomás de, Summa, cit. nota n. 19, 198.

${ }^{23}$ Aquino, Tomás de, Summa, cit. nota n. 19, pp. 198-199.

${ }^{24}$ Aquino, Tomás de, Summa, cit. nota n. 19, p. 198.

${ }^{25}$ Aquino, Tomás de, Summa, cit. nota n. 19, pp. 199-200. Igualmente Aquino, Suma Teológica, Tomo I, nota al pie $\mathrm{N}^{\circ} 2$, p. 250.

26 "en Dios la relación y la esencia no son cosa distintas, sino una sola y misma cosa" (AQuino, Summa Theologica, Tomo Primus, p. 198).

${ }^{27}$ Así OcCam, niega la relación in aliquo de Aquino (OcCAm, Guillermo de, Tratado sobre los principios de la teología, p. 87), considerando, en primer lugar, que Aristóteles sólo sostenía la relación ad aliquid (Occam, Guillermo de, Tratado sobre los principios de la teología, p. 86) ; y, en segundo, que todo predicado connota algo distinto del sujeto (Ibíd., p. 89). Fiel a su concepción nominalista, señala que al tratar las relaciones, se deben distinguir entre términos y cosas. Así, la relación sólo puede ser entre términos, más no entre cosas (Ibíd., p. 87), realizándose las distinciones entre relaciones, según sea quien la efectúa (Ibíd., p. 86). Además señala que los términos de una relación son correlativos, pero además derivables uno de otro pudiendo establecerse una inferencia silogística, como, por ejemplo, si alguien es padre, alguien es hijo (Ibíd., p. 88).
} 
esta relación última implicaría que al desentenderse de cosas o términos, la relación está lejos de pensarse de forma dependiente a dichos términos, por lo que debe entenderse con independencia de tales términos o cosas, lo que le da un carácter decididamente ontológico. Tanto es así que, subsistiendo su carácter de in aliquo, perfectamente puede ser ésta tanto ideal -como en el caso de la identidad, donde la relación es consigo misma ${ }^{28}$-, como real -en el caso en que se refiere a Dios ${ }^{29}$-, equiparándose en la taxonomía, de similar modo que la relación ad aliquid, donde ésta es ideal, como en las relaciones de igualdad y semejanza ${ }^{30}$, y real, ejemplificada en la cosa con relación a su gravedad ${ }^{31}$. Sin embargo, y no obstante que la relación in aliquo parece ser una exasperación o radicalización de este segundo concepto de relación dibujado por Aristóteles y que hemos venido señalando, lo cierto es que no es tan así. Esto porque la relación in aliquo tenía por finalidad dar una explicación coherente según las relaciones de Dios y la Trinidad, de cómo una relación puede ser no con cosas que se encuentren fuera de ella, sino consigo misma, que en el caso de Dios sería con él. Pero, además, intentaba extender el significado a la Trinidad: de cómo una cosa podía ser una y tres a la vez. Siendo así, y al final de cuentas, es posible para el aquinate una relación que se produzca dentro de una cosa ("Dios"), que pueda ser real (en cuanto a considerar a Dios como un ente de lo real y no únicamente ideal) e ideal a la vez, justificada a sí misma por el principio de identidad. Pero esta unidad es además una composición de tres, entendiendo a Dios como uno y como a la vez la Trinidad, la cual hipostáticamente lo conforma. Así, y al final de cuentas, no prescinde verdaderamente de términos de una relación, puesto que éstos serían, en el caso reseñado, los componentes Trinitarios.

Aquino nos sitúa, además, en un segundo momento teórico en cuanto a las relaciones, lo cual surge de otro proceso de distinción: lo absoluto y lo relativo. Si bien no clarifica ni especifica una forma lingüística para esta distinción -en cuanto habla de rem, secundum ${ }^{32}$, aliquo ${ }^{33}$, absoluto o relativo- recurre

${ }^{28}$ Aquino, Summa Theologica, Tomo Primus, p. 199.

29 "Et sic paternitas et filiatio sunt relations reales in divnis" (Ibíd., p. 199).

${ }^{30}$ Ibíd., p. 202.

${ }^{31}$ Así se produce una combinación de relaciones, que se grafica en la tabla:

\begin{tabular}{|l|c|c|}
\cline { 2 - 3 } \multicolumn{1}{c|}{} & real & ideal \\
\hline in aliquo & $\mathrm{X}$ & $\mathrm{X}$ \\
\hline ad aliquid & $\mathrm{X}$ & $\mathrm{X}$ \\
\hline
\end{tabular}

32 Aquino, Tomás de, Summa, cit. nota n. 19, p. 201.

${ }^{33}$ Aquino, Tomás de, Summa, cit. nota n. 19, p. 203. 
al criterio o argumento del "medio de los extremos" (medium inter ea) ${ }^{34}$ para señalarla. Dado a lo que, según cita de Aristóteles, donde "eadem via est de Athenis ad Thebas, et de Thebis ad Athenas" ${ }^{\prime 35}$, supone entonces lo absoluto, que dicho de otro modo significa que la razón entre la mitad de una relación a un extremo, es la misma que de la mitad al otro. Esto implica una relación absoluta. Pero no toda relación supone esta razón, ya que en ciertas relaciones, las razones medio-extremo no se identifican, sino que se diferencian cualitativamente. Esto último supone lo relativo o relaciones relativas. Médicis ${ }^{36}$ comentando a Aquino, distingue entre el medio absoluto del medio relativo, $y$, por ende, el medio absoluto determina una misma razón entre cualquiera de las cosas en relación y el medio, en cambio, en un medio relativo depende de los términos relacionados.

Al contar Aquino este grupo de relaciones dentro de su taxonomía, no hace sino enfatizar más, no en la relación en cuanto simple categoría, sino sobre todo, en el segundo tipo de relaciones a las que periféricamente se refiere Aristóteles. Fuera de los objetos que se encuentran a algún tipo de distancia (como en el caso de la relación absoluta), el efecto comparativo no es posible sino en la medida de tal distancia, producida a partir de los objetos, y no como mera representación categórica que sucedería con la semejanza, por ejemplo. La semejanza es una categoría y como tal, actúa de forma previa y con independencia de los objetos a los cuales haya de efectuarse la cualidad comparativa. En cambio, la distancia como concepto, deja su independencia de los objetos para tornarse más bien dependiente de ellos, porque dentro de dicho contexto es posible hablar de medium inter ea. Con lo cual tal tipo de relación no ahonda en tanto que categoría, sino más bien en cuanto al segundo tipo de relaciones esbozadas por el estagirita. Con ello Aquino, completa el cuadro apenas esbozado por Aristóteles al tratar de este tipo de relaciones, y le da un mayor y mejor tratamiento, sacándola de la oscuridad a la que la tenía relegada aquél.

\section{La relación bajo la mirada de la filosofía en la modernidad}

La relación como objeto principal y que se atisbaba como tal en parte del pensamiento del aquinate, finalmente se pierde posterior a la escolástica, y la dominación de la cosa en el racionalismo produce una subordinación sin contrapeso de la relación como categoría.

\footnotetext{
${ }^{34}$ Aquino, Tomás de, Summa, cit. nota n. 19, p. 203.

${ }^{35}$ Aquino, Tomás de, Summa, cit. nota n. 19, p. 202.

${ }^{36}$ Comentario señalado en Aquino, Suma Teológica, Tomo I, nota al pie N ${ }^{\circ}$ 1, p. 256.
} 
Por ejemplo, Bentham al utilizar la relación como categoría en la nomografía ${ }^{37}$, de igual modo Hume con sus seis categorías de relación ${ }^{38}$, y Descartes usada como categoría de forma corriente ${ }^{39}$. Si bien Kant no se aparta mayormente del concepto de relación aristotélico, ni de entenderlo en cuanto categoría y predicamento, siendo más bien "tradicional" a la concepción imperante ${ }^{40}$, sí extiende la significación de la relación, a las ya consideradas por Aristóteles y en la nomenclatura kantiana, de inherencia y subsistencia (susbtantia et accidens), comunidad (acción recíproca entre agente y paciente), la de causalidad y dependencia (causa-efecto) ${ }^{41}$, y al modo de ser concebida cognoscitivamente, dado a que, según Kant, una cosa no puede ser pensada atendiendo sólo a la categoría sino a la intuición externa que es la que nos da referencia para poder establecer una categoría de relación ${ }^{42}$, aunque relega a la relación-como señala Ferrer-al "dominio apriorístico de la pura razón" ${ }^{43}$ y, por ende, sigue existiendo en cuanto categoría.

No es sino hasta el socialismo científico, y en la fenomenología, donde la relación retoma una importancia decisiva.

Para Marx la relación y su concepto es resaltado y puesto en el tapete de la discusión de la filosofía económica, política y sociológica, situando a la relación como base del proceso económico y de los movimientos sociales. Esto le vale a Marx -según Engels- ser el descubridor de la relación para toda la Economía ${ }^{44}$. Marx centra su análisis tanto en las relaciones de producción como en las relaciones sociales, no bastando ni con señalarlas, ni con describir cómo se produce en las relaciones de producción -cuestión que hacen los "economistas burgueses ${ }^{\prime 45}$-, sino más bien en explicar cómo se producen tales relaciones ${ }^{46}$, cuestión que se logra mediante una investigación del movimiento histórico de dichas relaciones ${ }^{47}$, que a buenas cuentas se traduce en una interpretación de las relaciones desde la metodología del materialismo histórico. El vínculo entre

\footnotetext{
${ }^{37}$ Bentham, Jeremías, Nomografía o el arte de redactar leyes, pp. 4-10.

${ }^{38}$ Hume, David, Tratado de la naturaleza humana, Vol. I, pp. 102-104.

39 Descartes, René, Meditaciones Metafísicas, Las Pasiones del Alma, pp. 57-58.

${ }^{40}$ Ferrer Arellano, Joaquín, Filosofía de las relaciones jurídicas, p. 75.

${ }^{41}$ KANT, Inmmanuel, Crítica de la razón pura, p. 113.

${ }^{42}$ Kant, Crítica, cit. nota n. 41 , p. 255-258.

${ }^{43}$ Ferrer Arellano, Joaquín, Filosofía de las relaciones jurídicas, p. 72.

${ }^{44}$ Engels, Federico, La Contribución a la crítica de la economía política de Carlos Marx, p. 189.

${ }^{45}$ MarX, Carlos, Miseria de la filosofía, pp. 197-198.

${ }^{46}$ Marx, Miseria, cit. nota n. 45, pp. 197-198.

${ }^{47}$ MARX, Miseria, cit. nota n. 45, p. 198 y p. 205.
} 
relaciones de producción y todo otro tipo de relaciones es claro: Las relaciones materiales -tales como la oferta y la demanda que son relaciones de una determinada producción ${ }^{48}$ - y los modos de producción forman la base de todas las relaciones sociales ${ }^{49}$, las determinan ${ }^{50}$, y las condicionan ${ }^{51}$. "Es la sociedad-señala Marx-, son las relaciones basadas en el antagonismo de clases. Esas relaciones no son entre un individuo u otro, sino entre el obrero y el capitalista, entre el arrendatario y el terrateniente, etc. Suprimid estas relaciones y habréis aniquilado a toda la sociedad..." ${ }^{\prime 52}$. Por su parte, para Engels la Economía Política en cuanto ciencia, al acometerla o fundarla en el método dialéctico, se enfocaba ya histórica o lógicamente, sobre la relación económica para su análisis ${ }^{53}$. En tanto que relación, supone dos lados que han de estudiarse cada uno de forma separada "de donde luego se desprende su relación recíproca y su acción mutua" 54 , cuya solución ha de encontrarse en la creación de una nueva relación y así sucesivamente, lo cual es connatural a la concepción dialéctica que tanto Engels como Marx sustentan. Ahora, la relación en cuanto económica, supone entender que el concepto de mercancía no se encuentra fundada en la cosa transada en cuanto tal, sino que ésta se transforma en mercancía por la relación entre dos personas o comunidades, que es el productor, por una parte, y el consumidor, por otra ${ }^{55}$. Siendo así, la Economía así no trata de cosas, "sino de relaciones entre personas y, en última instancia, entre clases, si bien estas relaciones van siempre unidas a cosas y aparecen como cosas" [el resaltado es nuestro] ${ }^{56}$.

La discusión posterior que generaron las investigaciones de Marx y Engels, respecto a la relaciones, y sobre todo a la relación social, en cuanto no sólo denotarla sino explicar su generación, es luego una constante para toda la sociológica de allí en adelante, y para la tradición crítica posterior.

Es así como Foucault, por ejemplo, centra su discurso en otro tipo de relaciones que describirían el movimiento de la sociedad, como lo son las relaciones de poder. Así, tales relaciones de poder se extienden desde la sexualidad y la

\footnotetext{
${ }^{48}$ MARX, Miseria, cit. nota n. 45, p. 109.

${ }^{49}$ Marx, Carlos, Carta de Marx a Annenkov, p. 68; Marx, Carlos, Miseria de la filosofía, p. 223.

${ }^{50}$ MARX, Carta, cit. nota n. 49, pp. 69-70; 79-80.

${ }^{51}$ MarX, Miseria de la filosofía, p. 198.

${ }^{52}$ MARX, Miseria, cit. nota n. 45, p. 191.

${ }^{53}$ Engels, Federico, La Contribución a la crítica de la economía política de Carlos Marx, pp.188-189.

${ }^{54}$ ENGELS, La Contribución, cit. nota n. 53, p. 189.

${ }^{55}$ ENGELS, La Contribución, cit. nota n. 53, p. 189.

${ }^{56}$ Engets, La Contribución, cit. nota n. 53, p. 189. Igualmente en EnGels, Federico, Resumen del Tomo I de El Capital, p. 390.
} 
siquiatría hasta el derecho penal y penitenciario. La historia de la penalidad es fundamentalmente una historia de las relaciones entre el poder político y los cuerpos de los hombres ${ }^{57}$, en cuanto éstos son objeto de tales relaciones de poder ${ }^{58}$-que Foucault considera como compleja ${ }^{59}$, multívocas ${ }^{60}$, como una red de tensión ${ }^{61}$-, y como tal, objeto de ser afectados por el poder político y su dominación ${ }^{62}$, debido a ser considerados fuerza productiva a ser sometida. Las relaciones de apropiación Rey-cuerpo (como la cosa del Rey) y, por ende, directas, se truecan por relaciones indirectas de poder, o si se quiere transversales. Si en la "era del teatro de los castigos" ${ }^{63}$ la consecuencia era la apropiación del cuerpo y la manifestación en el exceso de poder, en la "era de la sobriedad punitiva" ${ }^{64}$ la consecuencia será la disciplina y la economía de las tecnologías punitivas. No castigar más, sino mejor. Con lo cual las relaciones de poder se modifican: no es el cuerpo de forma directa la intervenida por dicha relación, sino el alma del delincuente ${ }^{65}$, y de forma indirecta el cuerpo, al haber transformado el alma mediante la disciplina. Así tal relación de poder no se expresa como una relación directa entre el Estado y los individuos, sino que las relaciones con el poder se encuentran atomizadas, no como apropiación, sino como estrategia, como técnica y táctica, un poder que atraviesa e invade la sociedad ${ }^{66}$. Esto es, finalmente, la microfísica del poder. Uno de los mecanismos, una tecnología de poder que permita la distribución atomizada y homogénea del poder, para una disminución del coste penal del castigo mediante la vigilancia, es el panóptico. Habiéndose derivado Foucault este modelo de Bentham ${ }^{67}$, señala

\footnotetext{
${ }^{57}$ Foucault, Michel, La Vida de los hombres infames, p. 49.

${ }^{58}$ Foucault, Vigilar y Castigar, p. 30.

${ }^{59}$ Ibíd., p. 32

${ }^{60}$ Ibíd., p. 34

${ }^{61}$ Ibíd., p. 33

62 Ibíd., p. 32.

${ }^{63}$ Para las nomenclaturas adoptadas y la sistematización del pensamiento de Foucault para la periodización propuesta cfr. CARRASCO JiménEZ, Edison, El pensamiento penal de Foucault, p. 225.

64 Ídem.

${ }^{65}$ Foucault, Vigilar y Castigar, p. 132.

${ }^{66}$ Ibíd., pp. 33-34.

${ }^{67}$ El cual no sólo señala directamente los principios económicos que habrían de incardinar la penalidad ("Establecimientos propuesto para guardar los presos con más seguridad y economía..."; BENTHAM, Jeremías, El panóptico, p. 33), de igual modo la vigilancia como medio de utilización de panóptico ("La inspección: este es el principio único para establecer el orden [sic] y para conservarle; pero una inspección de un nuevo género que obra más sobre la imaginación que sobre los sentidos, y que pone a [sic] centenares de hombres en la dependencia de uno solo, dando a este hombre una especie de presencia universal en el recinto de su dominio", Ibíd., p. 35).
} 
que el panóptico es una construcción que tiene por finalidad crear y mantener un tipo de relaciones de poder ${ }^{68}$ de definir las relaciones de poder en la vida cotidiana de los hombres ${ }^{69}$ y de dar funcionamiento a dichas relaciones de poder $^{70}$, lo que finalmente no sólo redunda en control vigilante, sino además asegurar el funcionamiento de las relaciones de producción a través de dicha vigilancia que por su sola presencia genera relaciones de disciplina ${ }^{71}$. Busca este dispositivo, una nueva manera de sustituir la relación rey-cuerpo por la de cuerpo (individuo)-alma, donde el propio individuo, a través de la vigilancia a la cual es sometido, se disciplina, puesto quien es vigilado, sabiendo que es vigilado, reproduce las relaciones de poder de forma consciente y espontánea ${ }^{72}$. El panóptico no sólo tiene por objeto la perfección de las relaciones de poder en las cárceles, sino de forma general este modelo es replicado posteriormente en las construcciones de diversa índoles, como, por ejemplo, en los hospitales. El sistema carcelario se transforma así en un laboratorio que busca afinar las relaciones de poder y externalizarlas a la sociedad ${ }^{73}$. Las relaciones de poder igualmente se extienden hacia las relaciones laborales. El trabajo en la ciudad tiene por objeto que las relaciones de poder se internan en los trabajadores al moldearlos socialmente, con lo cual se hacen personas sumisas y controlables ${ }^{74}$, mejorando igualmente las relaciones de producción. Lo mismo tratándose del trabajo penitenciario que tiene por objeto disciplinar para el trabajo, y como tal, perfeccionar la relación de poder al afirmar y hacer posible en el recluso el que las relaciones de producción que serán interiorizadas ${ }^{75}$.

Las relaciones de poder se consumen en una relación de poder-saber. Existe una interacción entre el poder y el saber inescindible en cuanto todo poder involucra un saber y viceversa ${ }^{76}$, existiendo relaciones de superposición entre poder y saber $^{77}$. Los mecanismos de poder traen consigo un saber nuevo que se traduce en un mejor conocimiento ${ }^{78}$, como, por ejemplo, en los sistemas carcelarios donde a

\footnotetext{
${ }^{68}$ Foucault, Vigilar y Castigar, p. 204.

${ }^{69}$ Ibíd., p. 208.

70 Ibíd., p. 210.

${ }^{71}$ Ibíd., p. 211.

72 Ibíd., p. 206.

${ }^{73}$ Ibíd., p. 314

74 Ibíd., p. 301.

75 Ibíd., p. 273.

76 Ibíd., p. 36.

77 Ibíd., p. 189.

${ }^{78}$ Ibíd., pp. 227-228.
} 
través de la vigilancia se conoce mejor la conducta de recluido ${ }^{79}$, como de igual forma, el paciente en las instituciones siquiátricas. Ello produce conocer mejor el alma de quien se vigila ${ }^{80}$, y predecir, por esa forma, su conducta, con el objeto de disciplinarla y, por consecuencia, disciplinar el cuerpo. Así se produce, según Foucault, un cambio epistemológico ${ }^{81}$ consistente en un desbloqueo del espíteme, donde mientras mejore el saber, mejora el poder, produciendo el fenómeno inverso y dependiente de, si mejora entonces el poder, mejora el saber ${ }^{82}$.

Ya en el seno de la fenomenología, ésta habría de retomar la relación en cuanto objeto para las reflexiones de carácter más ontológicos y generales; primero, poniéndose en entredicho con Heidegger, una interpretación lineal de la cosa; segundo, otorgando a la relación, en Hartmann, el papel epistemológico perdido.

En la filosofía general, las apreciaciones de Heidegger sobre la "cosa", sitúa un punto de inflexión y discusión en el dominio de la cosa como centro del episteme. La constante referencia a la cosa como factor decisivo en la definición epistemológica, depende en gran parte del contenido óntico que se le quiere atribuir, y todo su supuesto se basa efectivamente en esta naturaleza óntica. En efecto, Heidegger discurre sobre ciertos significados equívocos -o multívocos- del término "cosa", extrayendo de la oscuridad en que habían dejado los griegos la acepción de "útil" para ella ${ }^{83}$. Este aspecto es interesante, sobre todo por los significados que logra determinar el filósofo alemán, en cuanto la cosa como útil, es "algo para", y como este "para" supone la necesaria referencia de algo a algo ${ }^{84}$.

Sin embargo, una cosa que es más bien "algo para" o "algo de algo" no se entiende precisamente representar un contenido óntico, sino todo lo contrario: dependiente, variable, sometido a las definiciones de ese algo. Pero si miramos desde la otra perspectiva, ese algo ante el cual la cosa se hace "para", no es susceptible del "útil", sino en cuanto se adecue a él igualmente. Así, lo que constituye el algo para el cual el útil sirve, se vuelve un útil del útil. Ni el "algo de" ni el "algo", pueden ser concebidos, dentro de ese contexto, sino en la medida en que son interdefinidos mutuamente como "algo de" y "algo". Esto significa que lo que se ha de llamar "cosas" no pudiendo ser definidos en sí mismos, carecen de todo contenido óntico. Sin embargo, parecieran tenerlo en sí mismo, por la costumbre de la experiencia de fijar cotas que permitan referenciar tal

\footnotetext{
${ }^{79}$ Ibíd., p. 210.

${ }^{80}$ Ibíd., p. 301.

81 Ibíd., p. 34.

82 Ibíd., p. 228.

${ }^{83}$ Heidegger, Martin, El ser y el tiempo, p. 81.

${ }^{84}$ Ibíd., p. 82.
} 
experiencia, inhibiendo luego la referencia, y centrando la experiencia sobre lo que Ilamamos "cosa", con lo cual parecen disponer de individualidad, sin poseerla verdaderamente. La referencia inhibida, es la relación. Es ella la que nos permite establecer una "individualidad" que es sólo aparente, a la que llamamos "cosas". Por ende, no son las cosas quienes disponen de un contenido óntico, puesto que es la relación que las Ilena de contenido óntico, pero sólo en apariencia, ya que es la relación en sí misma quien dispone de dicho contenido óntico, la cual es reflejada a las cosas. Las cosas así son dependientes, definidas por la relación, sometida a variaciones.

Sin embargo, es en Hartmann desde donde surge de la fenomenología, las reflexiones más ricas sobre la relación, y donde su centro de reconocimiento se sitúa sobre la "relación real", antes que meramente en la consideración secundaria como parte de una categoría ${ }^{85}$, existiendo en él una contraposición al pensamiento tradicional ${ }^{86}$. Es así como las formaciones naturales son fundamentalmente "relacionales" ${ }^{87}$, como "vinculaciones formadoras de estructuras en qué consiste su unidad" ${ }^{88}$, donde la relación se diferencia de lo relativo, como una formación por sí misma, en referencia de sus partes o miembros ${ }^{89}$. Lo relacional es así la "intrínseca constitución de todas las cosas materiales, en cuanto tienen cualquier configuración" [el resaltado es nuestro] ${ }^{90}$, donde la relación real se caracteriza por ser dinámica ${ }^{91}$, "interpenetrable" en sus formas ${ }^{92}$.

Todo lo reseñado dice relación con la filosofía, sin perjuicio de pensamientos que puede vincularse a enfoques sociológicos que han considerado la relación como elemento u objeto de sus investigaciones. Es así como con un carácter meramente descriptivo, la relación se inserta para explicar el funcionamiento

\footnotetext{
85 "y aun hasta la conciencia pensante, propenden a menospreciar categorialmente la relación real, tomándola en general tan sólo por una determinación secundaria y accidental de las cosas" (HARTMANN, Nicolai, Ontología Vol. IV. Filosofía de la naturaleza. Teoría especial de las categorías. (Categorías dimensionales. Categorías Cosmológicas), p. 288).

86 'La 'relación' en este sentido es algo enteramente distinto de toda mera referencia, en sentido activo o pasivo, tal como se entendía en la Antigüedad y durante toda la Edad Media, a saber, como algo secundario, como un hacer o decir subsidiariamente referencia a algo o hacia algo. No se trata del se habere ad aliquid del siglo XIII, en que se suponen las sustancias como inalterables, y se concebían sus referencias a otras sustancias como algo extrínseco a ellas o accidental" (Ibíd., p. 284).

${ }^{87}$ Ibíd., p. 284.

${ }^{88}$ Ibíd., p. 285.

${ }^{89}$ Ibíd., p. 284.

${ }^{90}$ Ibíd., p. 285.

${ }^{91}$ Ibíd., p. 286. Y como "relación fluyente" (Ibíd., p. 289).

${ }_{92}$ Ibíd., p. 287.
} 
de los sistemas desde la perspectiva de la teoría de los sistemas ${ }^{93}$, aunque sí relegada a un segundo plano ${ }^{94}$, como explicación sobre la forma y las características constitutivas de un complejo, sistema ${ }^{95}$ u organización ${ }^{96}$. Diferente es el caso de la denominada "teoría relacional" de Donati, la cual pretende, como teoría de las ciencias sociales, tener por objeto la relación en la explicación y comprensión de los fenómenos sociales ${ }^{97}$.

\section{Tratamiento De la Relación en el DereCho General: breVe PanOrama}

En el siguiente apartado se analizará el tratamiento que se le ha dado a la relación por las ciencias jurídicas. Si bien, y en estricto rigor, no podemos hablar de Montesquieu como un cientista jurídico, sus reflexiones no dejan de ser relevantes, más aún en el examen objeto de nuestro estudio. Es por ello que él inicia nuestra revisión. Luego, proseguirá con el postulado de la "relación jurídica" de Savigny, y la visión de ésta de la Neoescolástica Jurídica Española, de Kelsen y muy brevemente Santi Romano.

\section{Montesquieu y el espíritu de las leyes como una relación}

"El espíritu de las leyes" en Montesquieu, no es un estructura lingüística que suponga en ser simplemente, ni una alusión poética ni metafórica, sino que el autor la refiere a la forma de producción del derecho, esto es, al conjunto o

\footnotetext{
${ }^{93}$ BertalanfFy, Ludwig von, Teoría general de los sistemas, p. 55.

${ }^{94}$ De algún modo, la relación ante la teoría de sistemas se transforma en la "categoría" de las categorías del sistema, como una especie de categoría de primer orden. Luhmann refleja bien lo dicho en la aplicación de la teoría en los sistemas sociales, pero aun yendo más allá, relega a la relación a una importancia menor en contraste a la formulación de Bertalanffy, puesto que refiérese a la relación más bien como una simple categoría, de temporalidad y de complejidad, y de dependencia en los vínculos entre sistema y entorno, y entre los sistemas entre sí, un simple complejo o entramado sistémico, donde se sobre-ordenan en importancia sobre las relaciones la diferencia y/o la contingencia -aun hasta las relaciones de aplicación jurídica dependen de lo contingente- y la estructura, suponiendo esto último que incluso exista reversibilidad de las relaciones (LuHmanN, Niklas, Sistemas sociales. Lineamientos para una teoría general, pp. 41-42, p. 66, pp. 176-177, p. 314; LUHMANN, Sistema jurídico y dogmática jurídica, p. 61 y p. 83). Señala LUHMANN además: "un sistema diferenciado ya no consta propiamente de un determinado número de partes y de relaciones entre las partes, sino, más bien, de una mayor o menor cantidad de diferencias operativamente utilizables entre sistema y entorno" (LUHMANN, Sistemas sociales. Lineamientos para una teoría general, p. 32).

${ }_{95}$ Bertalanffy, Teoría general de los sistemas, p. 55.

${ }^{96}$ Maturana, Humberto; Varela, Francisco, El árbol del conocimiento. Las bases biológicas del conocimiento humano, pp. 36 y 40.

${ }^{97}$ Vid. DonatI, Pierpaolo, "Pensamiento sociológico y cambio social: hacia una teoría relacional", Reis, $N^{\circ} 63,1993$, pp. 29-52. Aunque en este último punto habría que constatar si se llegan a conclusiones diferentes usando la dialéctica.
} 
complejo de las relaciones de las leyes entre sí. "Lo que me propongo hacer en esta obra -señala Montesquieu- es examinar todas estas relaciones que, juntas, forman lo que se llama el espíritu de las leyes"98 [énfasis nuestro, excepto espíritu de las leyes del autor]. En primer lugar, y con algunas salvedades del pensamiento de Althusser ${ }^{99}$, Montesquieu determina su objeto de estudio que es este espíritu de las leyes, que según su propia declaración, es a fin de cuentas, un conjunto o la suma de relaciones, con lo cual, el objeto habría de ser representado en un orden macro, como el conjunto de relaciones, y en un orden micro, a la relación que forma este conjunto de relaciones.

Existen tres elementos fundamentales dentro del modelo de Montesquieu que explican la relación: a) el que las leyes son relaciones; b) el que las leyes tienen relaciones entre sí; c) el que las leyes tienen relaciones con las cosas de la experiencia (realidad no normativa).

a) El que las leyes son relaciones:

De que las leyes son relaciones (rapports ${ }^{100}$ ) lo dice expresamente: "Las leyes, en su más amplia significación, son relaciones necesarias que se derivan de la naturaleza de las cosas"101 [resaltado es nuestro]. En primer lugar, tal afirmación de leyes en cuanto relaciones, es novedosa, puesto que no existe, en este sentido, una conceptualización de ley simplemente en tanto reglas ${ }^{102}$, declaración o norma, sino que pese a involucrar este tipo de nociones a su constructo -sobre todo el de regla al derecho ${ }^{103}$ - lo cierto es que su idea generatriz, es más bien la relación como infraestructura y elemento centrípeto ${ }^{104}$. Esta cuestión no habría sido Ilamada en su atención por la ciencia del derecho, hasta ese momento. En segundo lugar, lo expresado por Montesquieu, trae de la mano a su vez dos

\footnotetext{
${ }^{98}$ Montesquieu, Del espíritu de las leyes, p. 11.

${ }^{99}$ Sin necesariamente contravenir todo el argumento de AlthusSER en torno al objeto de estudio de MONTESQUieu en Del Espíritu de las leyes, sí es necesario hacer unos alcances. El autor citado refiere el objeto a lo referido por el propio Montesquieu, esto es, que tiene por objeto "las leyes, las costumbres y los diversos usos de todos los pueblos de la tierra" (Althusser, Louis, Montesquieu: La política y la historia, p. 14). Tal apreciación, conjuntamente con la expuesta en el cuerpo del texto, no son contradictorias, sino complementarias. Esto porque el estudio no deja de ser las leyes, las costumbres y los diversos usos, por ser examinados en cuanto relaciones. Es la forma de mirar lo que supone estudiarlos en cuanto que relación, lo que comprende algo más que simplemente considerar a las leyes, costumbres y usos como objetos aislados.

100 Montesquieu, De L" esprit des lois, Tomo I, p. 5.

101 Montesquieu, Del espíritu de las leyes, p. 7.

102 Así en Aquino, La Ley, 3, p. 18.

${ }^{103}$ Montesquieu, Del espíritu de las leyes, p. 7.

${ }^{104}$ Esta novedad la analiza muy bien Althusser, el cual la denomina como "revolución teórica", ya que cambia el concepto de ley y engloba bajo este concepto a toda ley, sea natural o humana. Cfr. Althusser, Montesquieu: La política y la historia, pp. 33-49.
} 
cuestiones particulares: el que las relaciones son necesarias y el que se derivan de la naturaleza de las cosas. Si bien su referencia es a la ley en el sentido más amplio y general -sean éstas divinas, naturales o leyes de Gobierno (políticas y civiles)-, no por ello no deja de englobar las leyes políticas y civiles, dado al carácter omnicomprensivo y no exclusivo de su concepto. En lo tocante a las leyes civiles y políticas, no dejarían éstas de no ser entonces ni necesarias, ni derivadas de la naturaleza de las cosas. En cuanto relaciones necesarias, no son meras categorías, sino conditio sine qua non, requisito o presupuesto básico de su configuración. La derivación de la naturaleza de las cosas, pareciese suponer una condición invariable y constante, situada a la par que el del movimiento de las $\operatorname{cosas}^{105}$, y que además supone el reconocimiento de una acción recíproca entre las cosas que se encuentran en relación ${ }^{106}$. Siguiendo el razonamiento de Althusser ${ }^{107}$, se puede decir, que como no es la consideración de las leyes como esencia el objeto de estudio de Montesquieu, sino más bien de los hechos de los cuales se pueden deducir las leyes, asimismo, las relaciones que producen estas leyes son entonces concretas, relaciones inferidas de la experiencia (realidad).

b) El que las leyes tienen relaciones entre sí:

El que las leyes tengan relaciones entre sí, también lo señala de forma expresa: "las leyes tienen relaciones entre sí: con sus orígenes, con el objeto del legislador y con el orden de las cosas sobre las que se legisla"108. Entre sí -en la traducción del francés "entre elles"109_, implica que se produce una relación entre más cosas de la ley en sí misma, por ende, parece existir un orden de cosas dentro de una ley fuera de su aspecto meramente normativo, es decir, cuestiones que son componentes de su significado, sin necesariamente ser sólo norma. Estas cuestiones serían el origen, el objeto del legislador y el orden de las cosas sobre las que se legisla ${ }^{110}$.

Montesquieu no habla respecto del origen como historia de la ley, sino de origen (origine ${ }^{111}$ ). Ello nos podría conducir en estudiar la ley en cuanto que relación, no en su aspecto histórico, sino en un nivel más profundo, ya que implica ir al origen de la ley, a su génesis; si se quiere, a su herkunft como señala Nietzsche, a su tronco. No es estudio del origen de las sociedades, cuestión que indica las teorías originarias de la sociedad como las contractuales, cuestión que Montesquieu

\footnotetext{
105 Montesquieu, Del espíritu de las leyes, p. 7.

106 "las relaciones de su masa y su velocidad, aumentan, disminuyen o se pierden" (Ibíd., p. 7).

${ }^{107}$ Althusser, Montesquieu: La política y la historia, p. 16.

108 Montesquieu, Del espíritu de las leyes, p. 11.

109 Montesquieu, De L" esprit des lois, Tomo I, p. 11.

110 Montesquieu, Del espíritu de las leyes, p. 11.

111 Montesquieu, De L" esprit des lois, Tomo I, p. 11.
} 
repele ${ }^{112}$. Más bien, es el origen de la ley, de su formación en cuanto que relación o conjunto de relaciones, en cuanto origen de las relaciones concretas.

Tratándose del segundo tipo de relación, al hablar del objeto del legislador (I"objet du législateur ${ }^{133}$ ), pareciera referirse finalmente a la finalidad que dispone el legislador para una determinada legislación, cuestión que se vincularía entonces a las decisiones políticas, a la política legislativa en cada caso concreto.

El orden de las cosas a que Montesquieu se refiere (I"ordre des choses $\left.{ }^{114}\right)$, se relaciona con las diversos tipos de derecho, como el derecho natural, el derecho divino, el derecho eclesiástico, el derecho de gentes, el derecho político general y particular, el derecho de conquista, el derecho civil y el doméstico ${ }^{115}$. Las relaciones entre la ley y su orden, señala finalmente un proceso de distinción entre la cosa específica, y la ley que ha de relacionarse a ella. Mientras más depurado el proceso de distinción, mejor y más preciso será la relación producida entre la cosa y la ley ${ }^{116}$. Se podría inferir, según lo que expresa Montesquieu, la existencia de relaciones espurias entre las cosas y la ley a regularlas, es decir, que no exista necesaria correspondencia entre ambas, surgiendo relaciones imperfectas o impuras. Para aclarar este punto, denota el caso y la posibilidad de la existencia de leyes que aparentemente ser contradictorias entre sí, porque parecen regular una misma cosa, no lo son ya que responden a distintos órdenes. Así pone en contradicción aparente las leyes romanas que impedían recibir el marido a su mujer que había estado con otro hombre, y las leyes que permitían el préstamo de la mujer $y$, por ende, ser recibida por éste ${ }^{117}$. En el primer caso el recibimiento era castigado, en el segundo no; pero el primero es una ley civil, y en el segundo una ley política. Por ende, no había contradicción, porque respecto de la ley política el "objeto era dar a la República hijos de buena especie". Esto último indica la existencia de imbricaciones entre el "orden de las cosas" con el objeto del legislador, lo que vincularía el "orden de las cosas" a decisiones políticas. En este punto Montesquieu aparece presuntamente contradictorio. Esto porque pretende que el objeto del legislador, lo sitúe a distancias diferentes del orden de

\footnotetext{
${ }^{112}$ Cuestión declarada por MONTESQuieu en las Cartas Persas, y desestimada completamente con punto de base en Del espíritu de las leyes, como bien ha señalado Althusser (Althusser, Louis, Montesquieu: La política y la historia, pp. 28-31).

113 Montesquieu, De L" esprit des lois, Tomo I, p. 11.

114 Ibíd., p. 11.

115 Montesquieu, Del espíritu de las leyes, pp. 322-323.

116 "Hay pues diferentes órdenes de leyes; la sublimidad de la razón humana consiste en saber bien a cual de dichos órdenes se refieren principalmente las cosas sobre las que se debe estatuir, y en no sembrar la confusión en los principios que deben gobernar a los hombres" (Ibíd., p. 323).
}

117 Ibíd., p. 335. 
las cosas. Como ejemplo reducido al absurdo, no pretende que la patria potestad sea regulada por el derecho penal, porque el orden de la cosa sobre la que habría de legislar no encuentra correspondencia con la ley que la regule. En ello la impureza y contradicción de la relación es evidente. Pero en otros casos donde Montesquieu pretende llamar la atención sobre leyes que regulen una misma cosa diferente, podría existir algún tipo de contradicción, ya que finalmente la decisión es política sobre qué ley regular qué cosa, y dónde los límites, no siendo tan claros como en el ejemplo, pueden producir relaciones impuras por la contradicción entre objeto del legislador y orden de las cosas, entre la decisión legislativa y lo Ilamado a ser regulado, entre la política y la experiencia (realidad). De ahí que en el Libro XXVI Del espíritu de las leyes, Montesquieu se arroje a establecer criterios de distinción que permitan disponer de claridad a la hora de señalar dónde han de situarse el orden de las cosas, y dónde las leyes que hayan de regularlas.

c) El que las leyes tienen relaciones con las cosas de la experiencia (realidad no normativa)

Ahora bien, el que las leyes tienen relaciones con las cosas de la experiencia (realidad no normativa), no está dicho de forma expresa por Montesquieu, pero evidencia en toda su construcción. Al hablar de orden de las cosas, sin duda que piensa en que no sea simplemente relaciones entre leyes, sino que las relaciones sean con las cosas a las cuales haya de regular y regir. Lo mismo en el tema de la naturaleza de las cosas.

\section{El concepto de "relación" y/o "relación jurídica" en Savigny}

No es sino Savigny quien toma el término relación y la adjetiva al derecho transformándola como "relación jurídica"118, dándole el carácter con el que se le conoce para el mundo del derecho privado hasta el hoy, y con repercusiones en el derecho procesal ${ }^{119}$.

\footnotetext{
${ }^{118}$ Ferrer Arellano, Filosofía de las relaciones jurídicas, p. 68 y p. 72.

${ }^{119}$ Chiovenda, por ejemplo, consideraba la relación jurídica como vínculo entre personas existente con anterioridad al derecho, y que una vez regulado por este se hacía relación jurídica. Difería de la concepción privatista savigniana, al señalar que la relación jurídica no comprendía sólo en un derecho subjetivo, sino más bien en la comprensión de una multiplicidad de derechos subjetivos entre partes, lo cual hace entender a la relación jurídica como un "complejo" (CHIOvENDA, Giuseppe, Instituciones de Derecho Procesal Civil, Vol. I, p. 4). Esta relación jurídica puede ser tanto entre particulares como entre el Estado y los particulares (Íbid., pp. 3-4), que procesalmente y significando ya una "relación jurídica procesal", se traduce en una doble relación que se produce entre las partes del proceso ("relación jurídica sustancial"), y la relación entre el órgano jurisdiccional y las partes ("relación jurídica procesal"), estableciendo entre ambas relaciones procesales, "continuas interferencias y contraposiciones" (Íbid., p. 5). Carnelutti por su parte aplica iguales conceptos privatistas para el derecho procesal (CARNELUTTI, Francesco, Instituciones del proceso civil, Tomo I, pp. 289-291). En idéntico sentido Calamandrei (Calamandrel, Piero, Estudios sobre el proceso civil, p. 222).
} 
Pareciera que el centro del concepto de relación de Savigny lo caracteriza como "puntos de contacto" con el mundo exterior. "Esta relación -señala Savigny- tiene una naturaleza orgánica que se manifiesta, ya sea por el conjunto de sus partes constitutivas que se equilibran y limitan mutuamente, ya sea por sus desenvolvimientos sucesivos, su origen y sus descensos ${ }^{\prime 120}$. La relación entre seres humanos -"de la misma naturaleza y del mismo destino" - sería la más importante ${ }^{121}$. El derecho en esta relación parece ser un mecanismo regulador, como forma de asegurar su libre arbitrio en esta relación, "como una línea invisible de separación [que] determine los límites" de dicho desenvolvimiento libre de cada individuo ${ }^{122}$, con lo cual se conforma una relación de derecho. La relación de derecho así, sería "el dominio de la voluntad libre"123, "una relación de persona a persona, determinada por una regla jurídica" asignando a cada uno un espacio de dominio donde su voluntad reine de forma independiente de toda otra voluntad ${ }^{124}$. Pero no toda relación humana "entra en el dominio del derecho"125. Existen algunas que están plenamente sometidas al derecho, como la propiedad; parcialmente, como el matrimonio, o plenamente fuera de aquél, como la amistad.

Existen para Savigny, dos tipos de relaciones de derecho. La primera, es entre un hombre y la porción determinada de la naturaleza, Ilamada cosa, estableciéndose un derecho sobre la cosa denominado "propiedad"126, y que engendra un derecho sobre las $\operatorname{cosas}^{127}$. La segunda se descompone en dos a su vez: a) entre una persona y otra de forma aislada: esta relación entre una persona y otra, es una relación de dominio con otra pero no respecto de toda ella sino de alguno de sus actos, generando así lo que denomina "obligación"128; b) entre una persona y otra de forma orgánica: lo que supone la existencia de necesidad de plenitud existencial del hombre por falta de ella, la que la encuentra en sus vínculos con otros individuos determinados a completarse mutuamente, sea por la diferencia de sexos que se traduce en el matrimonio, sea por la reproducción que se traduce en el parentesco, dando origen al derecho de familia ${ }^{129}$. Tanto

\footnotetext{
${ }^{120}$ SAVIGNY, Friedrich Carlo Von, Sistema del derecho romano actual, Tomo I, § IV, p. 26.

121 Ibíd., § LII, p. 222.

122 Ibíd., § LII, p. 223.

123 Ibíd., § LIII, p. 224.

${ }^{124}$ Ibíd., § LII, pp. 223-224.

125 Ibíd., § LII, p. 224.

126 Ibíd., § LIII, p. 226.

127 Ibíd., § LIII, p. 231.

${ }^{128}$ Ibíd., § LIII, p. 227.

${ }^{129}$ Ibíd., § LIII, pp. 228-231.
} 
la propiedad como las obligaciones pertenecen al Ilamado "mundo exterior", en cambio, las relaciones de familias al "yo hecho más extenso", quedando "el yo", fuera del derecho positivo ${ }^{130}$. Esto lo imagina como círculos concéntri$\cos ^{131}$. Ceñidos al orden dispuesto por Savigny, la representación gráfica sería:

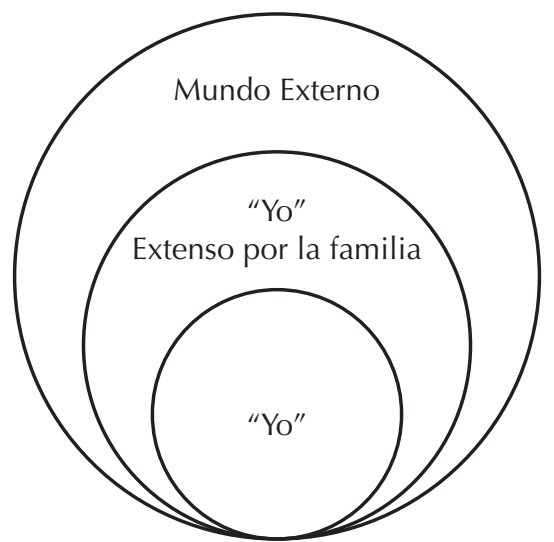

Fuera de ello, lo cual no es una crítica sino una salvedad, es la utilización del modelo de las relaciones jurídicas al derecho privado, cuestión que en su concepción es suficiente para la construcción de su modelo. Sin embargo, de seguir sólo este esquema -cuestión que se ha hecho con profusión desde los pandectistas alemanes ${ }^{132}$ hasta la actualidad de la discusión civilista ${ }^{133}$-, supone limitar los alcances del concepto relación y no extenderlo al ámbito del derecho público, cuestión que lejos de ser profusa, es referida sólo por algunos autores de los cuales haremos la mención en los apartados siguientes.

\footnotetext{
130 Ibíd., § LIII, p. 230.

131 Ibíd., § LIII, p. 230

${ }^{132}$ De los cuales Ferrer señala que se caracterizan por entender la relación jurídica como o relación social o un aspecto del derecho subjetivo, y por dejar de lado el elemento material de la relación jurídica (Ferrer Arellano, Joaquín, Filosofía de las relaciones jurídicas, pp. 167-168).

${ }^{133}$ Modelo que no ha cesado en su aplicación y orientado a interpretaciones diversas. Así, y para el retracto convencional, se plantea por Mateo Sanz, no diferentes consecuencias del modelo de Savigny, y aún reduciendo el problema relacional práctica y únicamente a sujetos. Así el autor define la relación jurídica como "el vínculo, situación o relación social reconocida por el ordenamiento jurídico como digna de tutela y útil para satisfacer intereses; de carácter unitario y complejo; de condición distinta y dependiente de los poderes y deberes que en ella se incluyen; que respecto a una realidad social liga a dos o más sujetos, uno de los cuales, exigente o pretensor, ocupa el lado activo y goza de un derecho subjetivo o poder -otorgado por el ordenamiento jurídico-, frente a otro u otros -sujeto/s pasivo/sque tiene/n un deber jurídico respecto al anterior, a cuyo cumplimiento puede/n ser compelido/s por el ordenamiento jurídico" (MATEO SANZ, Jacobo, El retracto convencional: relación jurídica y derecho subjetivo, p. 38).
} 


\section{Neoescolástica jurídica española ${ }^{134}$ y el concepto de relación}

La neoescolástica jurídica española se centra fundamentalmente en la relación jurídica como concepto. Mantienen en general la postura clásica sobre la relación jurídica, en término de derechos y obligaciones, y entre sujetos facultados y obligados ${ }^{135}$, enmarcados en un iusnaturalismo escolástico fundado en la ley natural y un fuerte contenido ético ${ }^{136}$.

González De Castejón distingue el sujeto activo, pasivo, el objeto del Derecho y la relación jurídica, señalando de ésta que es el "verbo del derecho mismo" en cuanto determina la "acción, pasión y movimiento del sér [sic] que la determina y del objeto sobre que recae"137. Considera la relación como externa y perteneciente al mundo exterior, ya que los hechos y actos producidos en ese mundo, son los que condicionan (modifican o extinguen) la relación jurídica ${ }^{138}$.

Mendizábal parece reconocer la existencia de las relaciones con anterioridad a la regulación jurídica, y por lo que se convierten en relaciones jurídicas ${ }^{139}$. Lo sitúa como un vínculo entre dos personas y nada más que entre dos personas ${ }^{140}$. Desde ya Mendizábal establece una diferencia entre las relaciones jurídicas entre sujetos que forman o modifican las relaciones, y una segunda en que existe un superior que impone su voluntad ${ }^{141}$, con lo cual formula con bastante anterioridad a Kelsen, las relaciones de coordinación y supraordinación de aquél.

\footnotetext{
${ }^{134}$ Nomenclatura tomada de LLANO TORRES, Ana, Concepto de derecho y relación jurídica en el pensamiento aristotélico tomista español de los siglos XIX y XX, Servicio de publicaciones de la Facultad de Derecho de la Universidad Complutense de Madrid, Madrid, 1997.

${ }^{135}$ GonZÁlez de CASTejón y Elío, Francisco Javier, Lecciones de Derecho natural, Lección XXIV, p. 77-80; Si bien referida al "vínculo de derecho", Mendizábal y Martín, Luis, Elementos de Derecho Natural, Parte primera, Lección 18, p. 200, y MendizÁbal y MARTín, Tratado de derecho natural, El derecho en la vida, Vol. II, p. 500; Mendizábal y Martín, Teoría General del Derecho, № 103 y 113, p. 111 y 116117; MendizÁbal y Martín, Tratado de derecho natural, Los principios jurídicos fundamentales, Vol. I, № 83 y 94 , p. 111 y 118.

${ }^{136}$ LLANO TORRES, Concepto de derecho y relación jurídica en el pensamiento aristotélico tomista español de los siglos XIX Y XX, p. 100.

${ }^{137}$ González de Castejón y Elío, Francisco Javier, Lecciones de Derecho natural, Lección XXIV, p. 77.

138 Ibíd., p. 78.

139 Mendizábal y Martín, Luis, Teoría General del Derecho, № 102, p. 110; Mendizábal y Martín, Luis, Tratado de derecho natural, Los principios jurídicos fundamentales, Vol. I, № 82, p. 110.

140 MendizÁbal y Martín, Luis, Tratado de derecho natural, Los principios jurídicos fundamentales, Vol. I, No 93, p. 118; Mendizábal y Martín, Luis, Teoría General del Derecho, № 112, p. 116.

141 Mendizábal y Martín, Luis, Teoría General del Derecho, № 108, p. 114; Mendizábal y Martín, Luis, Tratado de derecho natural, Los principios jurídicos fundamentales, Vol. I, № 88, p. 114.
} 
Cuestiones que son interesantes atisbar como visión de conjunto, en su posición general, son, por ejemplo:

- Cómo la relación es tomada, en algún caso, en cuanto componente definitorio en el concepto de derecho. Así García Amado define por derecho "la relación o conjunto de relaciones activas libremente establecidas para el fin de bien, propio de voluntad humana"142.

- En algunos de sus autores, se puede rastrear una discusión sobre la naturaleza de la relación, específicamente, sobre la naturaleza individual o social de los vínculos jurídicos, naturaleza que dependía según si a los derechos que correspondía la relación, eran considerados individuales o sociales. Así existía una concepción unitaria y binaria. La concepción unitaria, sostenida por Mendizábal, señalaba que la relación jurídica sólo tenía naturaleza social ${ }^{143}$, ya que fuera de la sociedad no existe derecho alguno y como tal, no cabe referirse a relación jurídica individual ${ }^{144}$. En cambio, la concepción binaria -González de Castejon ${ }^{145}$, Rodríguez de Cepeda- declara la existencia de ambas relaciones tanto individual como social.

- En otros autores, la sociedad es entendida no como una suma de individuos, sino en cuanto un todo orgánico semejante a un cuerpo viviente ${ }^{146}$.

\section{Kelsen y su concepto de "relación jurídica"}

De forma general Kelsen entiende la relación jurídica manteniendo como base para su comprensión, la concepción savigniana fundada en los términos de derecho subjetivo y obligación jurídica ${ }^{147}$.

Para Kelsen, las relaciones jurídicas no pueden entenderse sino dentro del ordenamiento jurídico ${ }^{148}$, ya que desde un punto de vista epistemológico meramente normativo, no existe más relación jurídica que las relaciones entre normas,

\footnotetext{
${ }^{142}$ Tomado en Llano Torres, ANA, Concepto de derecho y relación jurídica en el pensamiento aristotélico tomista español de los siglos XIX y XX, p. 21.

${ }^{143}$ Mendizábal y Martín, Luis, Principios de Derecho natural, pp. 24, 57, 64.

${ }^{144}$ Llano Torres, ANA, Concepto de derecho y relación jurídica en el pensamiento aristotélico tomista español de los siglos XIX y XX, p. 88.

${ }^{145}$ González de Castejón y Elío, Francisco Javier, Lecciones de Derecho natural, Lección LXVIII, p. 279.

${ }^{146}$ En cuanto a la sociedad como individuos coordinados Mendizábal y Martín, Principios de Derecho natural, pp. 24, 73, 121. Esta cuestión es igualmente destacada por Llano TORRES, Concepto de derecho y relación jurídica en el pensamiento aristotélico tomista español de los siglos XIX y XX, p. 101. En la precisión de la sociedad como organicidad cuasibiológica se señala en AGUIRRE OssA, José Francisco, El poder político en la neoescolástica española del siglo XIX, $\mathrm{N}^{\circ}$ 8, p. 629, $\mathrm{N}^{\circ}$ 17, p. 631.

${ }^{147}$ KeLSEN, Hans, Teoría pura del derecho, 32, pp. 174-177.

${ }^{148}$ Kelsen, Hans, Problemas capitales de la teoría jurídica del Estado, p. 615.
} 
y las relaciones "entre ciertos hechos determinados por normas jurídicas"149. En cuanto a relación entre normas, debido a que las normas contienen conductas, las relaciones normativas se producen final e igualmente -puesto que la conducta es el contenido de la norma ${ }^{150}$ - entre conductas $^{151}$. En cuanto relación a ciertos hechos, se refiere a las propiedades de ciertos hechos que poseen en relación a otros por el "puesto que ocupan en la norma" que por ende devienen en propiedades jurídicas ${ }^{152}$, en cuanto son aquellos donde el derecho produce ciertas relaciones fácticas entre individuos -como el matrimonio ${ }^{153}$, , pero que sólo tienen existencia y origen en el orden jurídico ${ }^{154}$. Con esto último Kelsen niega el que las relaciones se encuentren fuera del entramado jurídico, independientes por tanto del orden jurídico ${ }^{155}$, dado a que los sujetos están como partes de dicho orden ${ }^{156}$.

Distingue las relaciones jurídicas privadas y públicas. Tratándose de las relaciones jurídicas públicas, no se diferencian grandemente de las relaciones jurídicas privadas. La única diferencia que el mismo Kelsen advierte, es que mientras las relaciones privadas se producen por coordinación, las relaciones jurídico-públicas se establecen por supraordinación. En efecto, las relaciones jurídico-privadas se basan fundamentalmente en una relación entre sujetos coordinados $^{157}$, entre el sujeto de una obligación jurídica y aquel del correspondiente derecho subjetivo -razón que la obligación y el derecho subjetivo se corresponden por ser éste reflejo de aquélla ${ }^{158}$ - en cuanto uno está obligado a una determinada conducta respecto del otro, conducta que se encuentran enlazadas de un modo específico en una norma de derecho, en cuanto una es conducta en cuanto facultad, y la otra en forma de obligación ${ }^{159}$. Esta sería

\footnotetext{
${ }^{149}$ KeLSEN, Teoría pura del derecho, 32, p. 176 y 178.

150 Ibíd., 32, p. 175.

151 Ibíd., 32, p. 177.

${ }^{152}$ Kelsen, Hans, Teoría General del Estado, p. 140.

153 "Como puede observarse -señala Medina Morales-, estamos ante un concepto de relación jurídica que surge plenamente inmerso en el mundo del deber ser, y ajeno al mundo del ser, de modo que cualquier derecho que el marido pueda tener respecto de la mujer, o ésta respecto al marido (...) vendrá determinado por las reglas generales que regulan el matrimonio..." (Medina Morales, Diego, El derecho subjetivo en Hans Kelsen, p. 194).

${ }^{154}$ KeLSEN, Teoría pura del derecho, 32, p. 178.

155 Ibíd., 32, pp. 177-178; Kelsen, Teoría General del Estado, p. 139.

156 Kelsen, Teoría General del Estado, p. 139.

${ }^{157}$ Kelsen, Teoría pura del derecho, 32, p. 174; KelSEN, Teoría General del Estado, p. 138.

158 KeLSEN, Teoría pura del derecho, 32, p. 174.

${ }^{159}$ Kelsen, Teoría General del Estado, p. 139.
} 
la concepción tradicional en materia de relaciones jurídicas. Sin embargo, Kelsen pretende extender las posibilidades de dicho concepto -al cual señala de estrecho ${ }^{160}$ - al derecho público, y de ahí que sin dejar el concepto privatista, lo amplíe, como una triple posible relación entre los órganos legislativos (producción normativa) y los órganos judiciales y administrativos (aplicación normativa), entre éstos y los sujetos obligados por esos actos, y entre los individuos facultados de ejecutar los actos coactivos frente a los obligados por ellos. Esto puede perfectamente reducirse en una bipartición entre las relaciones entre la norma que obliga a los órganos en la producción de normas y éstos, y entre dichas normas y los sujetos obligados a ella (cuestión que finalmente se reduce a la clasificación normativa kelseniana en normas primarias y secundarias, como bien advierte Ferrer ${ }^{161}$ ).

No hay, en consecuencia, una relación ni de individuos -ya que Kelsen excluye la relación entre individuos o entre personas como relación jurídica ${ }^{162}$ - ni de subordinación entre individuos, sino que la subordinación se da más bien como una relación de la norma con los individuos, entre orden jurídico e individuos, ya que son las normas que establecen los derechos y deberes ${ }^{163}$. Como derechos y deberes, sujetos de derechos y deberes y como tal, las relaciones se posibilitan entre sujetos de derecho -no de individuos-, que para el caso del derecho público, son relaciones de poder entre el Estado y el súbdito, entre el sujeto superior y el subordinado ${ }^{164}$. Esta relación de derecho público así entonces es una relación de supraordinación.

En el aspecto penal -aunque Kelsen no lo señala pero las referencias a conducta y delito lo parecen acusar- esta relación se traduce en una relación entre un sujeto dotado de poder jurídico para demandar (sancionar/exigir sanción), y la conducta delictiva del individuo obligado por dicha conducta ${ }^{165}$. Esta relación se expresa de modo concreto en una supraordinación del individuo al Estado, teniendo éste el derecho de demandar determinada conducta de aquél como obligado a ella ${ }^{166}$.

\footnotetext{
${ }^{160}$ Kelsen, Teoría pura del derecho, 32, p. 174.

${ }^{161}$ Ferrer Arellano, Filosofía de las relaciones jurídicas, p. 153.

162 Kelsen, Teoría pura del derecho, 32, p. 176; Kelsen, Teoría General del Estado, p. 140. Como igualmente niega la relación como jurídica entre Estado y territorio, y si de considerarla en ese sentido, sólo en cuanto símil para efectos cuasi pedagógicos (KelSEN, Teoría General del Estado, p. 241).

163 KeLSEN, Teoría pura del derecho, 32, pp. 174-175.

${ }^{164}$ KeLSEN, Teoría General del Estado, p. 138.

${ }^{165}$ KeLSEN, Teoría pura del derecho, 32, p. 176.

166 Ibíd., 32, p. 177.
} 


\section{Las consideraciones de Santi Romano de las relaciones jurídicas}

Según Ferrer, Santi Romano extiende las consideraciones de la relación jurídica al derecho público a través de su concepto de institución, aunque no en su carácter de principal ${ }^{167}$. Efectivamente, Santi Romano, por ejemplo, no habla precisamente de la relación como definición o centro del concepto de derecho, sino de institución. Sin embargo, lo interesante es que para sustentar su teoría, recurre al concepto de organización y de relación. Por ello señala que el derecho "ante que implicar una simple relación o serie de relaciones sociales, es organización, estructura..."168. Ello enraizado en su concepto de ordenamiento jurídico como unidad pero no como suma de partes, sino más bien como algo distinto de los elementos que lo componen ${ }^{169}$ como un conjunto compuesto de mecanismos o engranajes y relaciones de autoridad o fuerza ${ }^{170}$. Esto lleva a pensar no sólo en la concepción orgánica del ordenamiento jurídico y aún sistémica, sino como las relaciones no las niega, sino que parece integrarlas dentro del concepto de organización, y de institución como concepto definitorio final. Pero además nos conduce en considerar que la idea de Santi Romano respecto de la relación, es más bien el carácter integrador de una organización. Sin embargo, niega a la relación como elemento central, último y definitorio del derecho: sólo ha de ratificar su carácter elemental en la medida que esté integrada a una organización.

\section{Observaciones a las posturas revisadas}

Montesquieu no centra su discusión necesariamente en hechos, sino más bien en relaciones, y en base a esto estructura su concepto de ley. Pero ello no concluye en ser formalmente una definición de ley, sino más bien la ley sería una derivación de cómo se produce en lo concreto el desenvolvimiento de la realidad (experiencia), dado a que las leyes se infieren de tal realidad, produciendo por consecuencia una alterna que es la realidad normativa. La realidad (experiencia) estaría conformada por relaciones, de las cuales se infieren a su vez las leyes, que por inferidas, son normativamente las relaciones que regulan o recogen de dicha realidad (experiencia). Debido a esto, las leyes por ello se definen igualmente como relaciones, porque no pudiendo apartarse de las relaciones que se producen en la realidad (experiencia), se estructuran de idén-

\footnotetext{
${ }^{167}$ Ferrer Arellano, Filosofía de las relaciones jurídicas, pp. 174-175.

168 Romano, Santi, L"Ordinamento giuridico, p. 27.

169 Ibíd., pp. 11-12.

${ }^{170}$ Ibíd., pp. 15-16.
} 
tica forma. Es por ello que la elaboración legislativa supone, por ese motivo, la producción de relaciones, que en este caso conforman una realidad propia, que es la experiencia normativa, pero con dependencia necesaria de la relación concreta de donde es inferida la ley.

Esta cuestión establece desde ya, un orden definido de relaciones, aquellas que Montesquieu describe como perteneciente a la correspondencia entre la realidad (experiencia) que sirve de base para la inferencia normativa, y tal inferencia ${ }^{171}$; es decir, a la relación entre estos dos órdenes. Como las relaciones de equidad existen antes que existan las leyes positivas que las establecen, supone que una vez inferidas, las leyes positivas sientan además un tipo de relaciones con las relaciones de equidad, sino no podrían regularlas y ser ellas mismas relaciones. De otra forma, si todas las leyes son relaciones que responden o son inferidas de relaciones posibles anteriores, supone entonces que necesariamente deben existir relaciones entre las leyes positivas y las relaciones que existen con anterioridad y a las que leyes positivas han de conformarse.

Sin embargo, ni ello hace posible resolver las contradicciones más profundas, de aquellas de límite difuso, y que tal vez por su falta de nitidez, por su poca claridad, puedan pasar desapercibidas. Pero más aún, ¿no sería necesaria la conservación del silencio en el que han quedado para su uso, e incluso disponerse de nuevos silencios, entrampar límites hacia lo difuso, con el fin de internar la discreción, la dexteridad y disimulación ${ }^{172}$ a la política legislativa? Tal vez se requiera que esta contradicción devenga en dialéctica pura, en puntos de tensión cuya superación sea resuelta en cada caso a favor de la política legislativa, pero por motivos mucho más amplios que sólo aquélla: por relaciones que irriguen de un líquido invisible, insentido dentro del caudal, pero que finalmente tenga su repercusión en la masa. Este ya presenta un problema topológico en las relaciones, que requiere de idéntica topología para poder llegar desde sus formas hasta las relaciones reales.

En cuanto a la postura de Savigny, es posible advertir algunos problemas en la construcción. En primer lugar, no existe una clara depuración de lo que se entiende por relación jurídica, ni tampoco por relación, salvo ciertos indicios muy someros, como la referencia a la conexión. Declara la importancia de la relación, señalando las consecuencias de aquélla, mas no el porqué de ella, ni explicación sobre su producción. Señala ciertos tipos de relación, pero parte de supuestos hasta cierto punto dados, denotativos de la relación, pero no demostrativos (como es del caso de estructurar sus sistematizaciones pos-

171 Montesquieu, Del espíritu de las leyes, pp. 7-11.

172 Álvarez-Ossorio Alaviño, Antonio, Milán y el legado de Felipe II, pp. 35-36. 
teriores sobre la relación jurídica en cuanto elemento material, olvidando el formal $\left.{ }^{173}\right)$. En segundo lugar, identifica relación con hecho ${ }^{174} \sin$ señalar las razones de tal identificación, no señalando tampoco la naturaleza de lo que conforma la relación, si estos mismos a su vez son hechos u otra cosa, ni determinando qué tipo de naturaleza de hecho supone ser la relación. En tercer lugar, incurre en algunas confusiones, como entre el concepto de relación y el dominio de la libre voluntad, con lo cual, según la denuncia de Ferrer, confunde relación con derecho subjetivo ${ }^{175}$; u otro tipo de confusión, donde señala la relación interpersonal como una relación entre personas y $\operatorname{cosas}^{176}$. En cuarto lugar, se presentan problemas de inexactitud, al simplemente describir el ámbito de relaciones en su concepción orgánica ${ }^{177}$.

Respecto de la posición sustentada por Kelsen, dado a que éste construye una teoría meramente formal, las relaciones que se producen son igualmente

\footnotetext{
${ }^{173}$ Idéntica previsión en Ferrer Arellano, Filosofía de las relaciones jurídicas, p. 162.

${ }^{174}$ Señala que la relación de derecho estaría conformada por una parte material que sería la relación, y por el derecho que sería la forma, donde "el primero [la relación] puede ser considerada como el elemento material de la relación de derecho, como un simple hecho..." (SAvIGNY, Sistema del derecho romano actual, Tomo I, § LII, p. 224).
}

${ }^{175}$ Ferrer Arellano, Filosofía de las relaciones jurídicas, p. 162.

176 Ibíd., p. 162.

177 Así, por ejemplo, toma como referencia explicativa la ley frater a frater señalando: "estando dos hermanos bajo el poder paterno, presta uno al otro una suma de dinero, la cual se paga después de la muerte del padre: se pregunta si hay derecho a repetir esta suma como indebidamente pagada. ¿Procede o no la conditio indebit? Tal es la única cuestión sometida a la apreciación del juez; pero para resolverla debe tener en cuenta el conjunto de relación del derecho, que se descompone de la siguiente manera: poder paterno sobre los dos hermanos, préstamo del uno al otro, peculio recibido del padre por el deudor. La relación de derecho se ha desenvuelto por la muerte del padre, la apertura de la sucesión, y el pago de la deuda. Tales son los diversos elementos cuya combinación debe entrar en la decisión del juez" (SAVIGNY, Sistema del derecho romano actual, Tomo I, § IV, p. 27). Según este ejemplo las relaciones producidas serían las siguientes: La primera es una relación de familia, que se traduce en el instituto de la patria potestad. La segunda, es una simple relación crediticia que se traduce en el concepto de obligación civil bajo condición. La tercera es una relación sucesoria, pero dependiente a su vez de la obligación, ya que la apertura de la sucesión es la condición. Todas son relaciones jurídicas, mas no todas personales, ya que en el último caso la relación es con el acervo hereditario. Sin embargo, la última de las tres relaciones no se especifica del todo. Si la intención es explicar las relaciones como detalles, puede valer, pero el problema se encuentra en que el caso propuesto ha sido descompuesto en diversas relaciones que se suponen integran de manera orgánica el instituto frater a frater. Siendo así, el cuadro explicativo carece de consistencia sistemática, ya que las relaciones se muestran explicativamente aisladas. Por otro lado, el poder paterno no tiene incidencia como relación orgánica desde que la obligación condicional y la apertura de la sucesión completan el cuadro, donde el poder paterno es deducible perfectamente tanto de la obligación como del hecho de la apertura. La relación mostrada por Savigny es en este sentido trivial y superflua, si lo que se quiere es establecer relaciones que funciones dentro de una organización, como es del caso presentado por él. Dicho de otro modo, la patria potestad es una relación, pero no es orgánica en el caso propuesto por Savigny y, por ende superflua. 
formales ${ }^{178}$, o se mueven en un ámbito formal y normativo ${ }^{179}$, de tal modo que no dejando espacio a las relaciones sociales en cuanto no sean jurídicas, políticas o psicológicas de poder ${ }^{180}$, y manteniendo una "tajante separación" en la relación entre la realidad social y la estructura jurídica ${ }^{181}$, en aras de la "divinidad" del sollen, invalida -aunque sin negarlas- las relaciones producidas fuera de lo normativo, y vacía de contenido crítico a la relación, sobre todo al existir las relaciones sociales y producirse las relaciones de poder ${ }^{182}$. No puede negarse, por otro lado, la inexistencia de relaciones entre el mundo de lo jurídico, y lo social, ya que lo jurídico no mantiene un corpus segregado de lo social, como si no pudiese producirse ningún tipo de relación con lo social o lo político. Plantearlo de ese modo es prácticamente ilusorio y no representa el movimiento de los fenómenos sociales, y como el derecho se mueve en ellos, o a pesar de ellos.

Ahora bien, si ambas posturas se analizan replicando los esquemas para el derecho penal, entonces se transforma en un programa inviable. El modelo presentado por Savigny, no explicaría, dentro de la ciencia penal, cómo ciertas relaciones jurídicas plenamente sometidas al derecho, no cubren todo el ámbito de significaciones del derecho penal, sino que son consideradas parcialmente. En este caso están las relaciones de propiedad. Las llamadas relaciones de propiedad, son primeramente relaciones entre un hombre y la cosa, cuestión que le da presupuesto a una relación jurídica llamada relación de propiedad. Si bien los conceptos definitorios tienen sentido dentro del derecho, en este caso el término "propiedad", para que ello haya llegado a designarse y tratarse como tal, se necesita de una relación que sea antes que nada producida en la experiencia, sin la cual, la relación de derecho sería un sin sentido ${ }^{183}$. El derecho penal considera antes que la relación de propiedad, la

178 "El derecho subjetivo -señala KeLSEN-, es simplemente forma y no contenido", donde la relación jurídica es "pura y exclusivamente (...) relación formal que el orden jurídico crea" (KeLSEN, Problemas capitales de la teoría jurídica del Estado, p. 615).

${ }^{179}$ Como en idéntico sentido afirma Ferrer (Cfr. Ferrer Arellano, Filosofía de las relaciones jurídicas, p. 151) y Medina Morales (Medina Morales, El derecho subjetivo en Hans Kelsen, p. 195).

${ }^{180}$ KeLSEN, Problemas capitales de la teoría jurídica del Estado, p. 613. Advertido igualmente en MeDINA Morales, El derecho subjetivo en Hans Kelsen, pp. 61-62.

${ }^{181}$ Errázuriz Mackenna, Carlos José, La teoría pura del derecho de Kelsen, Visión crítica, p. 221.

182 Señala KeLSEN: "La construcción jurídica no puede ni debe, en modo alguno, esforzarse en captar los elementos políticos de poder que se esconden detrás de estas relaciones o forman su contenido, por la misma razón por la que ni puede, en el campo de derecho privado, captar los factores de orden económico"(Kelsen, Problemas capitales de la teoría jurídica del Estado, p. 614).

${ }^{183}$ Señalemos que los conceptos definitorios de propiedad si bien señalados por el derecho, estos antes que jurídicos son sociales, y en la medida de ellos, lo jurídico establece conceptos definitorios. Si entendemos que lo jurídico establece definiciones propias con independencia de lo social -que es lo que parece pretender KELSEN-, entonces, lo jurídico se constituye en un sistema definitorio arbitrario, que puede construir sus conceptos a espaldas de la experiencia, tornándose en una especie de pequeño déspota. Los 
relación entre el hombre y la cosa. Si en un primer momento la relación de propiedad es importante para determinar, por ejemplo, un delito contra la propiedad y, por ende, con caracteres definitorios, lo cierto es que el derecho penal no la identifica totalmente con ella, desde que considera aspectos como la cognición que ha tenido el sujeto respecto de la cosa, es decir, si tomó la cosa creyéndola suya siendo de otro, cuestión que dogmática y sistemáticamente es un error de tipo, pero que supone que la solución dogmática no pasa por las consideraciones entre el hombre y la propiedad -caso en el que habría que considerar como simplemente hurto, y como tal una acción típica y antijurídica-, sino entre el hombre y la cosa. La relación de propiedad, en tanto completamente sometida al derecho, no daría todo el ámbito de significaciones a que la ciencia penal concibe a una relación de tal naturaleza, esto porque no la concibe en términos de reducirla a una relación jurídica en términos savignianos, sino que le otorga una significación mucho más amplia y que acude al tipo de relación que es anterior y base de una relación jurídica, esto es, a la relación entre una persona y la cosa.

Por otro lado, la trasposición del esquema savigniano del derecho privado al público que hace Kelsen, nos parece inadecuado, porque el primero responde a categorías que no dispone el segundo, como, por ejemplo, el concepto de derechos subjetivos y de obligación ligados a ellos. Cuando se aborda el derecho penal dentro de este esquema, disponer que quien comete el delito es un obligado respecto del Estado, que es quien puede exigir la sanción como sujeto que demanda la obligación, nos parece incurrir en un reduccionismo del fenómeno penal inaceptable, que no se condice con las propias instituciones del derecho penal, sino que se trata de hacerlo responder, en primer lugar, al cuadro del derecho público como conjunto y, en segundo lugar, al esquema savigniano que, como decíamos, es elaborado preferentemente para el derecho privado.

La expresión puramente formal de las relaciones jurídicas, impide que se expanda el contenido de la relación a una relación de significado y de sentido, más allá que la simple expresión de vínculos dentro de la legalidad.

\section{Hacia la relación como objeto para la CienCia penal}

A nuestro juicio, el Derecho se ha reducido interpretativamente a la cosificación, cuestión que responde a la propia expresión de la filosofía occidental, con lo cual replica de algún modo sus contenidos. Los conceptos así, en Derecho, se reducen significativamente al ser especificados terminológicamente como "cosas", y en algunos casos la herencia más tradicional del derecho privado ha extendido sus raíces hacia el derecho penal, al cosificar la realidad jurídica.

conceptos son directrices, ley en cuanto reducido a normas, pero no por ello no dejan de ser parte de un vademécum científico, y que pueden ser sometidos a crítica y a su falsabilidad constantemente. 
La dirección propuesta es la de considerar a la relación como central, y no como un "objeto" científico periférico, tal como lo ha hecho la generalidad del pensamiento filosófico y jurídico. Muy por el contrario a la categoría, establecer los niveles ónticos de interpretación como relación real en el sentido hartmanntiano. Ello, porque los significados se expanden al considerar la relación como objeto antes que meramente como categoría, y la relación antes que la cosa, como "objeto" de la ciencia jurídica y penal.

La relación expresa una realización de sentido, que sin entender o centrar el estudio en la relación no surgiría, o entendiendo sus nodos por separado, toman otras significaciones totalmente diferentes, lo que el viejo adagio de que el "todo es la suma de las partes", es un error, tanto por entender que el sentido depende de las partes, o que un "todo" es ónticamente resultado de las partes, cuestión metafísica dado que ni sabemos cuál es el todo, ni sabemos que las partes tengan por sentido fundar un todo. Lo que se hace es entender la expresión de la realidad como un tejido, en el cual se "fijan" ciertas relaciones que entendemos enfocar.

Si bien para la relación social bastaría la trama epistemológica construida desde el pensamiento marxiano para dar predicación social del contenido de la relación, para el derecho penal pueden establecerse ciertas bases, pero que deben ser precisadas a la luz del campo normativo.

Es obvio que dentro de la ciencia penal, ciertos aspectos un tanto obvios se reconocieran como relaciones, como, por ejemplo, en los casos de concurso, ya que no hay posibilidad de referir el establecimiento analítico de dos o más disposiciones sino a través de sus relaciones lógicas. Y de hecho, cuando ha de hablarse de características específicas es también obvia la referencia a las relaciones si se trata de una categoría secundaria, según hemos ya hecho alusión. Lo que se trata de advertir es que no existe otra opción sino de entender que el objeto de la ciencia penal es la relación, la que por concebirse dentro del espacio del derecho penal, habría de adjetivarse como relación penal. Lo anterior es dicho por algunas razones.

En primer lugar, una disposición normativa no puede verse más que como un simple trozo de texto, un conjunto de palabras, de gesticulaciones (el gesto de la mano entre el sujeto emisor y el receptor "stop", por ejemplo, en el policía que dirige el tránsito) o de un signo (la señalética). En este nivel no pasa de ser un objeto. Pero la disposición normativa como tal, conceptualizada de ese modo, deja de ser entendida objetualmente, para adquirir toda una red de significados, de los cuales, el núcleo de esos significados es aquello que se dispone normativamente. Esto implica previamente, un conjunto de inferencias que ya no pueden consentir en una apreciación objetual de la disposición normativa, sino que es necesario establecer diversas relaciones de decodificación, según las relaciones que presente aquella, respecto de la cual se producen relaciones 
sintácticas y semánticas cuando trátase de un texto o de un conjunto de palabras, o de relaciones semióticas cuando trátase de una gesticulación o de un signo. Las relaciones interpretativas a nivel primario que realiza el sujeto, se "encuentran" con las relaciones lingüísticas de las disposiciones normativas y que definen ese trozo de texto, ese conjunto de palabras, ese gesto o ese signo como una disposición normativa.

Las especificaciones hacen que esa disposición normativa adquiera significaciones diferenciadas, según la clase de relaciones específicas que se produzcan dentro de una disposición normativa. Tales especificaciones son definidas según el contexto lingüístico como extralingüístico, los cuales hacen declarar las relaciones de sentido, y como son recíprocamente declarados por ellas. Así las diferenciaciones por área (civil, penal) como por hechos, determinan que una disposición normativa tenga una u otras relaciones significativas. Es lo que ocurre con las disposiciones normativas de carácter penal.

Pero fuera de entender la disposición normativa como un conjunto de relaciones, y ella en sí misma como una relación, la dogmática representa ya un nuevo conjunto de relaciones hermenéuticas que, ya no a nivel primario sino experto, sistematizan así la experiencia normativa, la cual se ve acrecentada con toda teoría del delito y de la pena, que se traducen en constituir un tejido explicativo, donde ya las relaciones conceptuales e interpretativas establecen un diálogo con las relaciones de sentido que a nivel primario las disposiciones normativas son capaces de ofrecer a la hermenéutica. Así la ciencia penal misma, es a su vez un tejido explicativo, un conjunto de relaciones teóricas que se ensamblan e interactúan para explicar la experiencia sobre la relación penal en cuanto objeto, y según la especificidad de acuerdo a lo examinado.

Por ejemplo, dentro del campo de la dogmática, y tratándose de las "relaciones normativas" -según como ha sido acuñado el término en la tradición hispánica por Sánchez Tomás ${ }^{184}$, y a la que nos plegamos aquí-, la ciencia penal alemana en Feuerbach ha reconocido las posibilidades de interpretación entre las penas como una relación (verhältniss) ${ }^{185}$ y, por ende, en tanto objeto de ciencia.

Si la misma disposición normativa dentro del espacio del campo normativo del derecho penal, ha de representar relaciones de significado, ya el objeto de

\footnotetext{
${ }^{184}$ SÁnchez Tomás, José M., "Relaciones normativas de exclusión formal y de especialidad: La problemática del error sobre elementos que agravan la pena a través del ejemplo del error sobre la edad de doce años (violación-estupro)", Anuario de Derecho Penal y Ciencias Penales, Tomo 46, Fasc/Mes 2, 1993, pp. 679-696.

${ }^{185}$ Feuerbach, Paul Johann Anselm Ritter von, Tratado de Derecho penal común vigente en Alemania, Parte General, [trad. Raúl Zaffaroni e Hagemeier], Colección "Criminalistas perennes", Editorial Hammurabi, Buenos Aires, 1989, pp. 134-137.
} 
la ciencia penal (y aun de la filosofía penal) no podría ser otro que una relación normativa. Las disposiciones normativas, leyes, normas -en sentido bindigniano o no-, son particularizaciones en el universo de la relación normativa, especies del género o elementos del universo.

Bustos, por ejemplo, considera la relación social como base de la definición jurídico-penal. Esto no puede ser de otra forma cuando lo que importa dentro de su sistema son las relaciones sociales concretas y determinadas que no son más que "la posición concreta que en la relación social determinada ocupan los individuos"186. De ahí a la consideración del bien jurídico como "síntesis normativa determinada de una relación social concreta y dialéctica"187, y si síntesis de relaciones, relación en sí misma, puesto que de qué otra manera habría de sintetizar algo -relaciones- y aun dialécticamente. Lo mismo si se piensa en su teoría del sujeto responsable, donde la base es precisamente la relación concreta y determinada de un sujeto social ${ }^{188}$. La responsabilidad, bajo dicha teoría, no podría pensarse sino en tanto relación. Todo lo dicho vale igualmente para Hormazábal (y obviamente para todo el Ilamado sistema Bustos-Hormazábal ${ }^{189}$ ).

Las aportaciones del sistema Bustos/Hormazábal, más el abrirse la ciencia penal al sentido de las relaciones normativas como objeto de la dogmática, puede construir interpretaciones que pueden expandir el significado dogmático y político-criminal de la ciencia penal, con lo que la solicitud de Kaufmann que las relaciones sean el objeto de la ciencia del derecho ${ }^{190}$-con lo que de paso haría coincidir los modelos teóricos que la expliquen en cuanto relaciones ${ }^{191}$, no parecería tan extraña, después de todo, para la ciencia penal.

\section{BiBLIOGRAFÍA}

Aguirre Ossa, José Francisco, El poder político en la neoescolástica española del siglo XIX, Colección Jurídica, Ediciones Universidad de Navarra, Pamplona, 1986.

\footnotetext{
${ }^{186}$ Bustos Ramírez, Juan, Control Social y sistema penal, p. 174.

187 Bustos Ramírez, Manual de Derecho Penal, Parte general (4º edición), p. 121.

188 Ibíd., pp. 508-511.

${ }^{189}$ Matus, Jean Pierre, Derecho penal y criminología y política criminal en el cambio de siglo, Colección de Ciencias Penales, Editorial Jurídica de Chile, Santiago, 2011, p. 19.

190 "El objeto de las ciencias normativas (...) no son nunca sustancias, sino relaciones. Es preciso que el gran paso dado por Peirce, desde la lógica kantiana y aristotélica, que sólo conoce predicados de cualidades, a la lógica de predicados de relación (...) se traslade también a la filosofía y a la teoría del derecho" [el resaltado es del autor] (Kaufmann, Arthur, Panorámica histórica de los problemas de la filosofía del derecho, p. 139).

${ }^{191}$ Nagel citado por NeumanN, Ulfrid, La teoría de la ciencia jurídica, p. 358.
} 
Althusser, Louis, Montesquieu: la política y la historia, Traducción $M^{a}$ Ester Benítez, $2^{\circ}$ ed., Editorial Ariel, Barcelona, 1974.

Álvarez-Ossorio Alaviño, Antonio, Milán y el legado de Felipe II, Historia, Sociedad estatal para la conmemoración de los centenarios de Felipe II y Carlos V, Madrid, 2001.

Aquino, Tomás de, Summa Theologica, Taurini, Italia, 1820.

, Suma Teológica, Traducción Hilario Abad de Aparicio, Moya y Plaza, Editores, Librería Imprenta, Madrid, 1880.

Suma Contra Los Gentiles. Traducción Jesús M. Pla. Castellano. Vol. I, Biblioteca De Autores Cristianos, La Editorial Católica, Madrid, 1952.

1958.

La Ley, Traducción Marcelino Ortiz, Editorial Tor, Buenos Aires, , Los Mandamientos, Traducción Salvador Abascal, $2^{\circ}$ ed., Editorial Tradición, Madrid, 1981.

, Suma De Teología, Traducción Ángel Martínez Casado y otros, $2^{\circ}$ ed. Bilbioteca de autores cristianos, Madrid, 1993.

La Ley, Traducción Fernández-Alvar, Editorial Labor, Barcelona, 1936.

Aristóteles, "Categorías", Tratados De Lógica, El Organon, Editorial Porrúas, México, 1972, pp. 23-46.

- La Metafísica De Aristóteles, Traducción Valentín García Yebra, I Vols, Biblioteca Hispánica de Filosofía, Editorial Gredos, Madrid, 1970.

México, 1972.

,"Tópicos" Tratados De Lógica, El Organon, Editorial Porrúas, ,Política, Traducción Manuel García Valdés, Vol. 116, Biblioteca Clásica Gredos, Editorial Gredos, Madrid,1988.

Madrid, 1995.

Física. Traducción Guillermo R. de Echandía, Editorial Gredos, Metafísica, Traducción Hernán Zucchi, Debolsillo, Buenos Aires, 2004.

Avicena, "Sobre metafísica". Traducción Miguel Cruz Hernández, Revista de Occidente, Madrid, 1950.

Bentham, Jeremías, El Panóptico, Traducción S/T, La piqueta, Madrid, 1979.

Bentham, Jeremías, Nomografía o el arte de redactar leyes, Traducción Cristián Pabón, Colección Clásicos Políticos, Centro de estudios Políticos y Constitucionales, Madrid, 2004.

BertalanfFY, Ludwig von, "Teoría general de los sistemas", Traducción Juan Almela, Colección Ciencia y teconología, Madrid: Fondo de cultura económica, 1993. 
Bustos Ramírez, Juan, Manual de derecho penal, Parte General, $4^{\circ}$ ed., España: Promociones y Publicaciones Universitarias (PPU)), Barcelona, 1994. Control Social Y Sistema Penal, Colección El Sistema Penal, Promoción Publicaciones Universitarias (PPU), Barcelona, 1987.

Calamandrel, Piero, Estudios sobre el proceso civil, Traducción S.S.M, Editorial Bibliográfica Argentina, Buenos Aires, 1945.

CARneluti, Francesco, Instituciones del proceso civil, Traducción Santiago Sentis Melendo, Ediciones Jurídicas Europa-América, Buenos Aires, 1956.

Carrasco Jiménez, Edison, "El Pensamiento penal de Michel Foucault". Revista Polis, Santiago de Chile, pp. 223-239, 2008.

ChIOvenda, Giuseppe, Instituciones De Derecho Procesal Civil. Traducción Orbaneja, $1^{\circ}$ ed. Vol. III., Editorial Revista de Derecho Privado, Madrid, 1940.

Descartes, René, Meditaciones Metafísicas, Las pasiones del alma, Traducción Consuelo Bergés, Ediciones Orbis, Barcelona, 1981.

Donatı, Pierpaolo, "Pensamiento sociológico y cambio social: hacia una teoría relacional", Reis, N ${ }^{\circ} 63,1993$, pp. 29-52.

Engels, Federico, "Resumen del Tomo I de El Capital", Marx, Escritos Económicos Varios, Editorial Grijalbo, México D.F., 1966, pp. 389-425.

"La Contribución a La Crítica de la economía política de Carlos Marx" Marx, Escritos Económicos Varios, Editorial Grijalbo, México D.F.,1966, pp. 183-190.

Errázuriz Mackenna, Carlos José, La teoría pura del derecho de Kelsen, Visión Crítica, Colección Jurídica, Ediciones Universidad de Navarra, Pamplona, 1986.

Ferrer Arellano, Joaquín, Filosofía de las relaciones jurídicas, Estudio General de Navarra, Ediciones Rialp, Madrid, 1963.

Feuerbach, Paul Johann Anselm Ritter von, Tratado de Derecho penal común vigente en Alemania, Parte General, [trad. Raúl Zaffaroni e Hagemeier], Colección "Criminalistas perennes", Editorial Hammurabi, Buenos Aires, 1989

Foucault, Michel, Vigilar y Castigar, Traducción Aurelio Garzón del Camino, Siglo veintiuno editores, Buenos Aires, 2002.

La Vida De Los Hombres Infames, Traducción Julia Várela y Fernando Álvarez-Uría, Caronte Ensayos, Editorial Altamira, La Plata, 1996.

González De Castejón Y Elío, Francisco Javier, Lecciones De Derecho Natural, Imprenta de los hijos de M.G. Hernández, Madrid, 1898.

Hartmann, Nicolai, Ontología, Traducción José Gaos. Vol. IV. Filosofía de la naturaleza. Teoría especial de las categorías. Categorías dimensionales. Categorías Cosmológicas, Fondo de cultura económica, México D.F., 1960. 
Heidegger, Martin, El ser y el tiempo, Traducción José Gaos, Sección de obras de filosofía, Fondo de Cultura Económica, Madrid, 2001.

Hume, David, Tratado de la naturaleza humana, Traducción Félix Duque, $2^{\circ}$ ed. Vol. I, Colección clásicos del pensamiento, Ediciones Orbis, Barcelona, 1985.

Kant, Immanuel, Crítica de la razón pura, Traducción Pedro Ribas, Clásicos Alfaguara, Ediciones Alfaguara, 1978.

KaUfmanN, Arthur, "Panorámica histórica de los problemas de la filosofía del derecho", Kaufmann (ed.), El Pensamiento Jurídico Contemporáneo, Editorial Debate, 1992, Madrid, pp. 47-142.

Kelsen, Hans, Teoría Pura Del Derecho, Traducción Roberto J. Vernengo, $2^{\circ}$ ed., Instituto De Investigaciones Jurídicas, Universidad Nacional Autónoma de México, México D.F., 1986.

Teoría Pura Del Derecho, Traducción Roberto J. Vernengo, $7^{\circ}$ ed., Editorial Porrúa), México D.F., 1993.

Teoría General Del Estado, Traducción Luis Legaz Lacambra, 24 vols, Colección "Crítica Del Derecho", Sección "Arte Del Derecho", Editorial Comares, Granada, 2002.

Problemas capitales de la teoría jurídica del Estado, Traducción Wenceslao Roces, Estudios Doctrinales, Editorial Porrúa, México D.F., 1987.

Llano Torres, Ana, Concepto de derecho y relación jurídica en el pensamiento aristotélico tomista español de los siglos XIX Y XX, Servicio de publicaciones de la Facultad de Derecho de la Universidad Complutense de Madrid, Madrid, 1997.

Lummann, Niklas, Sistemas Sociales. Lineamientos Para Una Teoría General, Autores, Textos Y Temas Ciencias Sociales, Antrophos, Barcelona, 1984.

Marx, Carlos, Miseria De La Filosofía, Traducción Tomás Onaindia, 281, Biblioteca Edaf, Madrid, 2004.

"Carta De Marx a Annenkov", Marx, Miseria de la filosofía, Biblioteca Edaf, Madrid, 2004, pp. 65-87.

Mateo Sanz, Jacobo, El retracto convencional: relación jurídica y derecho Subjetivo, Dykinson, Madrid, 2000.

Maturana, Humberto; Varela, Francisco, El árbol del conocimiento. Las bases biológicas del conocimiento humano. $1^{\circ}$ ed, series de ciencia, Editorial Debate, Madrid, 1990.

Matus, Jean Pierre, Derecho penal y criminología y política criminal en el cambio de siglo, Colección de Ciencias Penales, Editorial Jurídica de Chile, Santiago, 2011.

Medina Morales, Diego, El Derecho Subjetivo en Hans Kelsen, Córdoba, España, Servicio de Publicaciones Universidad de Córdoba, 2005. 
Mendizábal Y Martín, Luis, Principios de derecho natural, Biblioteca de Manuales Enciclopédicos Gili, Barcelona, Juan Gili Editor, 1903.

Teoría General Del Derecho, Zaragoza, Tip. La Editorial, 1915. Tratado De Derecho Natural, Los Principios Jurídicos Fundamentales, Vol. I., Imprenta y encuadernación de Julio Cosano, Madrid, 1920. Elementos de derecho natural, Parte Primera, Imp. y Lib. de la viuda de cuesta é hijos, Valladolid, 1890.

Tratado De Derecho Natural, El Derecho en la Vida, Vol. II., Imprenta y encuadernación de Julio Cosano, Madrid, 1920.

, Del Espíritu De Las Leyes, Traducción Mercedez Blázquez y Pedro de Vega, Edited by pensamiento, Editorial Tecnos, Madrid, 1993.

De L" Esprit Des Lois, Classiues Garnier, París, 1949.

Neumann, Ulfrid, "La Teoría De La Ciencia Jurídica", Traducción María José Fariñas Dulce, El Pensamiento Jurídico Contemporáneo, Kaufmann, Arthur; Hassemer, Winfried (ed.), Editorial Debate, Madrid, 1992, pp. 351-364.

Occam, Guillermo de, Tratado sobre los principios de la Teología. $2^{\circ}$ ed, Biblioteca De Iniciación Filosófica, Aguilar, Buenos Aires, 1962.

Exposición sobre los ocho libros sobre la física (Prólogo), Los Sucesivos, Ediciones Orbis, Barcelona, 1993.

Romano, Santi, L"ordinamento Giuridico, I Classici Del Diritto, Sansoni, Firenze, 1962.

SÁnchez Tomás, José M., "Relaciones normativas de exclusión formal y de especialidad: La problemática del error sobre elementos que agravan la pena a través del ejemplo del error sobre la edad de doce años (violación-estupro)", Anuario de Derecho Penal y Ciencias Penales, Tomo 46, Fasc/Mes 2, 1993, pp. 679-696.

Savigny, Friedrich Carlo von, Sistema Del Derecho Romano Actual. Traducción Jacinto Mesía y Manuel Poley, Madrid: F. Góngora y compañía editores, 1878. 